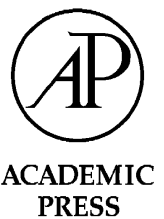

Available online at www.sciencedirect.com

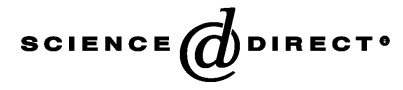

Journal of Sound and Vibration 271 (2004) 959-984

\title{
The acoustics of racing engine intake systems
}

\author{
M.F. Harrison ${ }^{\mathrm{a}, *}$, A. Dunkley ${ }^{\mathrm{b}}$ \\ ${ }^{\text {a }}$ School of Engineering, White Building, Cranfield University, Cranfield, Bedfordshire MK43 $0 A L, U K$ \\ ${ }^{\mathrm{b}}$ Ilmor Engineering Ltd, Quarry Road, Brixworth, Northants NN6 9UB, UK
}

Received 20 May 2002; accepted 14 March 2003

\begin{abstract}
Naturally aspirated racing engines have tuned intake systems and can now achieve volumetric efficiencies in excess of $125 \%$ and peak engine speeds in excess of $18,000 \mathrm{rev} / \mathrm{min}$.

Engines designed for single seater racing commonly dispense with the intake manifold and its convoluted and restricting flow path preferring single lengths of pipe feeding each cylinder separately.

An investigation into the intake process on a single cylinder racing engine has shown that inertial ram effects make a strong contribution to the intake process at high engine speeds whereas acoustic resonance effects are more important to the rather weak wave action that occurs at low engine speeds. An acoustic model of the resonant wave action has proved useful in distinguishing between these two effects. The attributes of the acoustic model have been compared to those of more traditional time-marching gasdynamics calculation methods.

A decoupled hybrid method has been shown to yield calculations of the wave dynamics in the intake system of a single cylinder racing engine that show fair agreement with measured results up to the 10th harmonic of the engine cycle frequency.

In a case study, the intake characteristics of a single cylinder racing engine have been shown to differ only slightly from those expected from the V10 engine on which it is based, although this will only be the case when the dimensions of the intake system are chosen appropriately.

(C) 2003 Elsevier Ltd. All rights reserved.
\end{abstract}

\section{Introduction}

Naturally aspirated racing engines have tuned intake systems and can now achieve volumetric efficiencies in excess of $125 \%$ and peak engine speeds in excess of $18,000 \mathrm{rev} / \mathrm{min}$.

Engines designed for single seater racing commonly dispense with the intake manifold and its convoluted and restricting flow path preferring single lengths of pipe feeding each cylinder

\footnotetext{
*Corresponding author. Tel.: + 44-1234-754-699; fax: +44-1234-750-425.

E-mail address: m.harrison@cranfield.ac.uk (M.F. Harrison).
} 
separately. In the main, the engine tuning process involves the selection of an appropriate pipe length along with the sizing and timing of the intake (and exhaust) valves in order to harness the unsteady flow in the intake to produce improved volumetric efficiency.

The V10 Formula 1 engine sits a little way behind the driver. Ten short lengths of vertically aligned intake pipe feed the ten cylinders. These pipes are contained in an airbox of several litres capacity located directly over the engine. This airbox is fed with air collected from above the driver's head and delivered by a large flared air-horn that is about three-quarters of $1 \mathrm{~m}$ long.

Traditional trial and error tuning on the dynamometer is nowadays supported by engine simulations on the computer. These take account of the unsteady flow in the intake (and exhaust) pipes as well as the unsteady mass transfer through the valves using one-dimensional (1D) models in the time domain [1]. The special requirements for such simulations when applied to racing engines have been investigated [2] and good agreement has been found between measured and calculated pressures in the intake systems of high-speed engines. Notwithstanding this, most engine developers still rely on engine tests to verify and extend the results from simulations. For the very high performance engines such as the $600 \mathrm{~kW}$ V10 used in Formula 1 racing it is convenient to test single cylinder engines, being in essence one cylinder sawn off the V10. A sketch of the intake portion of such an engine is shown in Fig. 1.

The advantage of the single cylinder engine is a much lower running cost. A Formula 1 engine has a service life of only 1 or $2 \mathrm{~h}$ when operating at full load. After that time, a near complete rebuild of the engine is required. The cost advantage of the single cylinder engine comes from a much reduced rebuild time and the need for service parts (bearings, piston, piston rings, seals) for only one cylinder rather than ten.

For the single cylinder engine sketched in Fig. 1 a large plenum (30 litre) is placed at the open end of the flared intake pipe to reproduce the effect of the 30 litre airbox on the V10. Dynamic pressure measurements made in the plenum of the running engine show only slight fluctuations in pressure compared with the large fluctuation seen in the intake pipe [3]. This suggests that the plenum is large enough to attenuate the fluctuating pressure amplitude at that location. It is commonly hoped that this attenuation means that the intake pipes are effectively decoupled from the remainder of the intake system, which normally includes an air conditioning unit to control

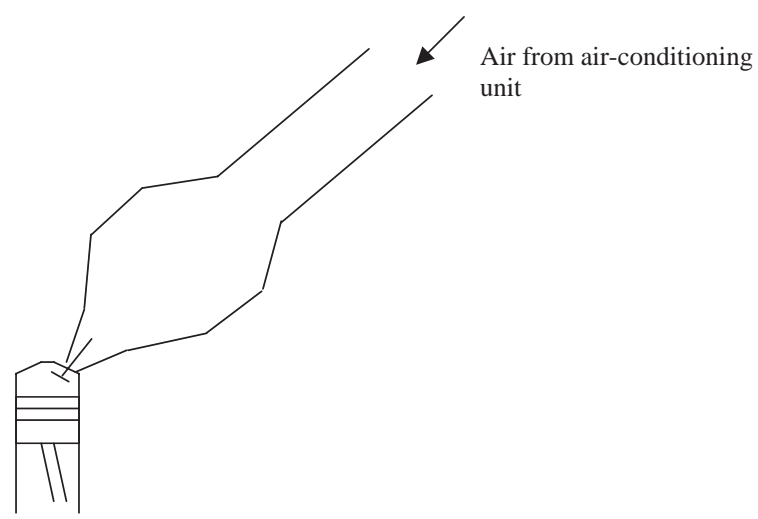

Fig. 1. Layout of the single cylinder Formula 1 intake system. 
the temperature, pressure and humidity of the air delivered to the engine. It is also commonly hoped that the airbox on the V10 performs the same decoupling function.

The main difficulty with the use of a single cylinder engine is that the measured performance does not closely match that obtained with the V10 [3]. The reasons for this have been investigated $[3,4]$. The first reason is simply that the friction levels per cylinder are higher in the single cylinder engine due to the extra mechanical systems (such as balance shafts) required to balance the engine. The second reason is the absence of exhaust tuning effects found with the V10 where five cylinders in a bank empty into a common exhaust pipe. The third reason, which is the subject of this paper, is due to the unsteady cyclic nature of the intake flow. The term 'wave action' is commonly used to describe such flow and it comprises two effects: resonant acoustic behaviour and an inertial ram effect'.

The inertial ram effect has been reported before. Dennison [5] found that the optimum supercharging effect occurred with a pipe of only $52 \%$ of the length that Capetti predicted would yield the lowest resonance frequency of a simple intake pipe using his resonant wave action theory [6]. On the basis of this he rejected the theory of resonance as being of "little more than academic interest" when it came to improving engine performance and he developed a theory of supercharging by inertia effects. His calculations, based solely on inertia effects, did not match his experimental results very well.

Taylor et al. [7] expanded the investigation to take account of both inertial and acoustic resonance effects. Both were found to be important, the relative importance of each varying with engine speed and intake pipe length. Variations with valve timing and with inlet pipe diameter were also reported. For operating conditions yielding the greatest volumetric efficiency, their results showed the inertial ramming effect to be the most significant.

Wave action in intake (and exhaust) systems is most conveniently calculated using a timemarching solver to the well-known gas-dynamic equation [1]. In this way, both resonant acoustic and inertial ram effects are considered. Such solvers form the basis for engine performance simulation methods, of which several computer codes are available commercially.

A commercial engine simulation code (known as AVL Boost) has been used to calculate the intake wave dynamics in a single cylinder Formula 1 engine [4]. The code uses a finite-volume shock-capturing scheme [8] as the wave action solver and is taken to be a good representative example of the current state of the art in such codes.

Fig. 2 shows the pressure time history measured in the intake port of the single cylinder Formula 1 engine sketched in Fig. 1, operating at 10,000 rev/min wide-open throttle. The results of two engine simulations are also shown where the gas exchange in the cylinder, the combustion, and the intake and exhaust wave action have been included in the modelling. In the first model, only the intake port geometry is included, neglecting the 301 plenum and the air horn beyond. In the second model, the full intake geometry is included. The results from the two simulations are very similar to each other and both broadly agree with the measured results, although some differences in detail are obvious. The degree of agreement shown was only found when the intake port was modelled as a $175 \mathrm{~mm}$ long section of pipe whereas its physical length was known to be $150 \mathrm{~mm}$. The need for such 'end corrections' has been noticed in other simulations of this type $[2,4]$.

On the basis of validation such as this, engine simulations of this type have been commended for use in racing engine design and development. However, a study of the theoretical background 


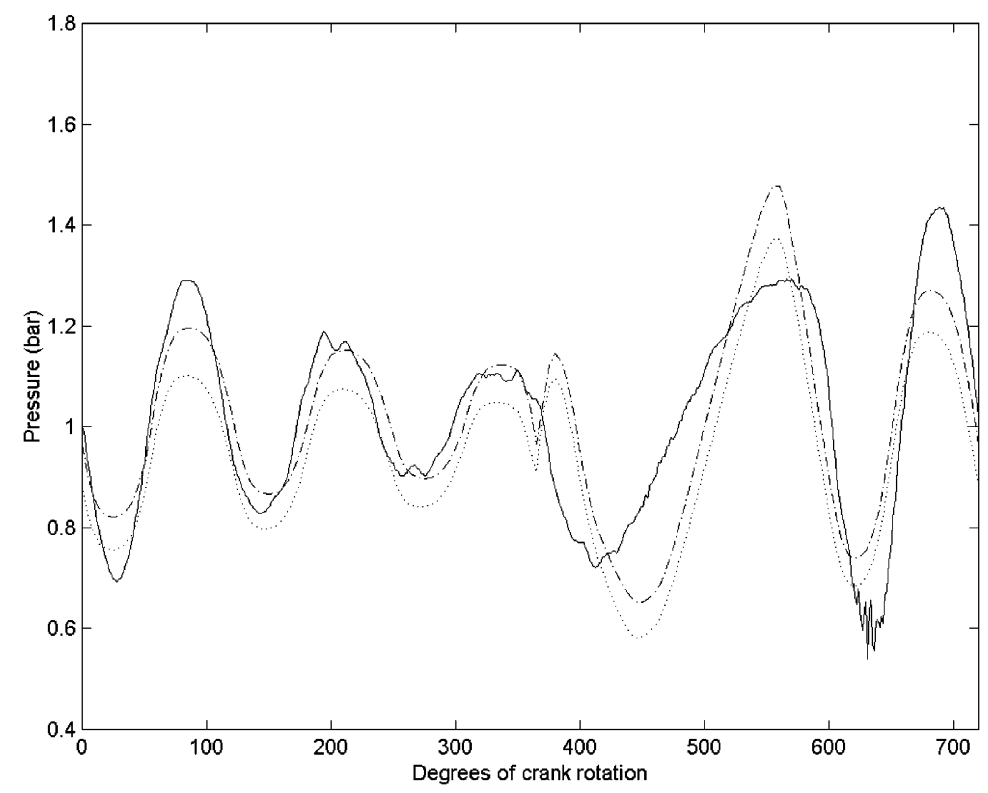

Fig. 2. Measured intake pressure (solid line) in the port of a single cylinder Formula 1 engine at $10,000 \mathrm{rev} / \mathrm{min}$ versus engine simulation results modelling the full intake system (dashed line) and just the intake port (dotted line).

to current engine simulations has identified areas where the realism of the modelling might be improved.

At present, the gas conditions in intake system plena tend to be calculated in the same manner as the gas exchange in the cylinder. The plenum is treated as a zero dimensional volume and rates of mass inflow/outflow are calculated using an idealized model of the flow through an orifice that is corrected using empirical flow coefficients. This has important implications. Firstly, the plenum has no length and therefore higher frequency acoustic resonances cannot be modelled and, secondly, the results obtained are strongly determined by the choice of inlet and outlet flow coefficients. In Fig. 2, inlet and outlet flow coefficients were somewhat arbitrarily set to a value of 0.95. Lower values would have reduced the fluctuating intake pressure amplitudes obtained from the model.

At present, the rate of inflow to the intake system is calculated assuming stagnation conditions outside the duct [1]. The implications of this are: firstly, the resulting quasi-steady state model is unlikely to be fully realistic in racing engines where the intake valve actuates at a frequency of $150 \mathrm{~Hz}$ at 18,000 rev/min; secondly, the intake air is gathered from above the driver's head in an airstream that is far from stagnant, having a race-average velocity approaching $60 \mathrm{~m} \mathrm{~s}^{-1}$.

In order to begin to address some of these issues, a linear acoustic model has been employed here to calculate the intake wave action in a single cylinder Formula 1 engine. The relevant attributes of the method are: firstly the model for the inflow to the system is dynamic, being bounded by an acoustic reflection coefficient that varies with frequency; secondly, plena are modelled with a length dimension and thus wave action therein is included; and thirdly the method is simple thus providing an alternative insight into intake wave action that might otherwise be hidden in the time-marching numerics of conventional engine simulations. 


\section{The acoustics of the intake system}

Consider the intake system of the single cylinder engine as sketched in Fig. 1. If the engine were disconnected from the air-conditioning system then the acoustics of the V10 installation in the car could be approximated by feeding the plenum with air directly from the dynamometer cell via a large bore straight walled pipe the same length as the air-horn. This has been tested [3]. The cone angles of the flared inlet and outlet of the plenum are large enough to suggest the adoption of a simplified model of the intake system as shown in Fig. 3.

Figs. 4 and 5 show intake pressures measured on the single cylinder engine at 13,000 and $7000 \mathrm{rev} / \mathrm{min}$ respectively. In each case, measurements were made using a piezoresistive pressure transducer (Kistler type 4045A2) in the short intake pipe near to the back of the intake valve(s). A crank-shaft encoder was used to divide the pressure records so obtained into short lengths, each one being the data relating to a different four-stroke cycle. These data sets were ensemble averaged to obtain an average pressure record for one full cycle and labelled with the key valve events (intake valve opening (IVO), intake valve closing (IVC), exhaust valve closing (EVC)) and the important piston positions $\left(90^{\circ}\right.$ after top dead centre (ATDC) where the piston velocity is greatest and bottom dead centre (BDC) where it is instantaneously zero).

The intake pressure record in Fig. 4 has certain features that are similar to intake pressures measured on another single cylinder engine running at low speeds [9]. Firstly, there is a decaying pressure oscillation in the period IVC-IVO. Secondly, there is a pressure depression centred on $90^{\circ}$ ATDC corresponding to the maximum piston velocity. Thirdly, there is a pressure peak just before IVC. However, the peak found at 13,000 rev/min with this engine is different from the one found at $2000 \mathrm{rev} / \mathrm{min}$ on the low speed engine [9]. The height of the peak on the low speed engine matched the depth of the depression that preceded it suggesting the dominance of an acoustic oscillation about the prevailing stagnation pressure. In the racing engine, the height of the peak $(0.6$ bar $)$ is much larger than the depth of the depression $(0.25$ bar $)$. This suggests that in addition to there being an acoustic oscillation present, there is some transfer of momentum in the late intake flow that causes a pressure rise behind the closing intake valve(s). That effect (often called inertial ram) seems to account for 0.35 bar of the 0.6 bar pressure peak and therefore seems to be the dominant effect at this engine speed.

The conclusions reached by Taylor et al. [7] are in line with the observations made with respect to Fig. 4. The speed of $13,000 \mathrm{rev} / \mathrm{min}$ corresponds to the speed region of very high volumetric

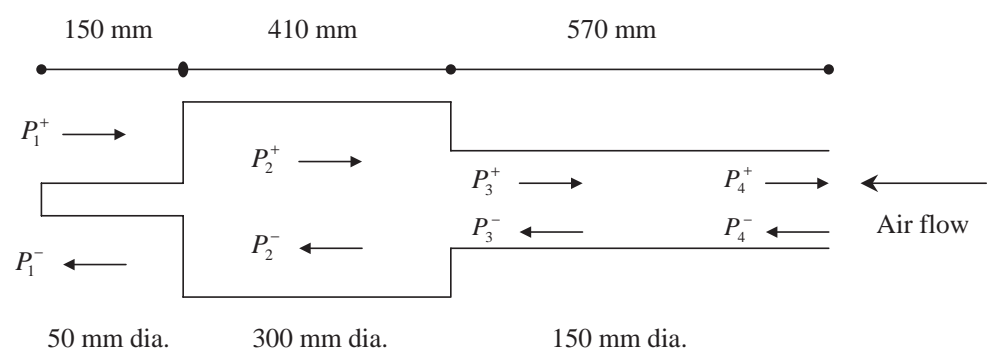

Fig. 3. Simplified geometry of the full intake system to the single cylinder Formula 1 engine used for acoustic modelling. 


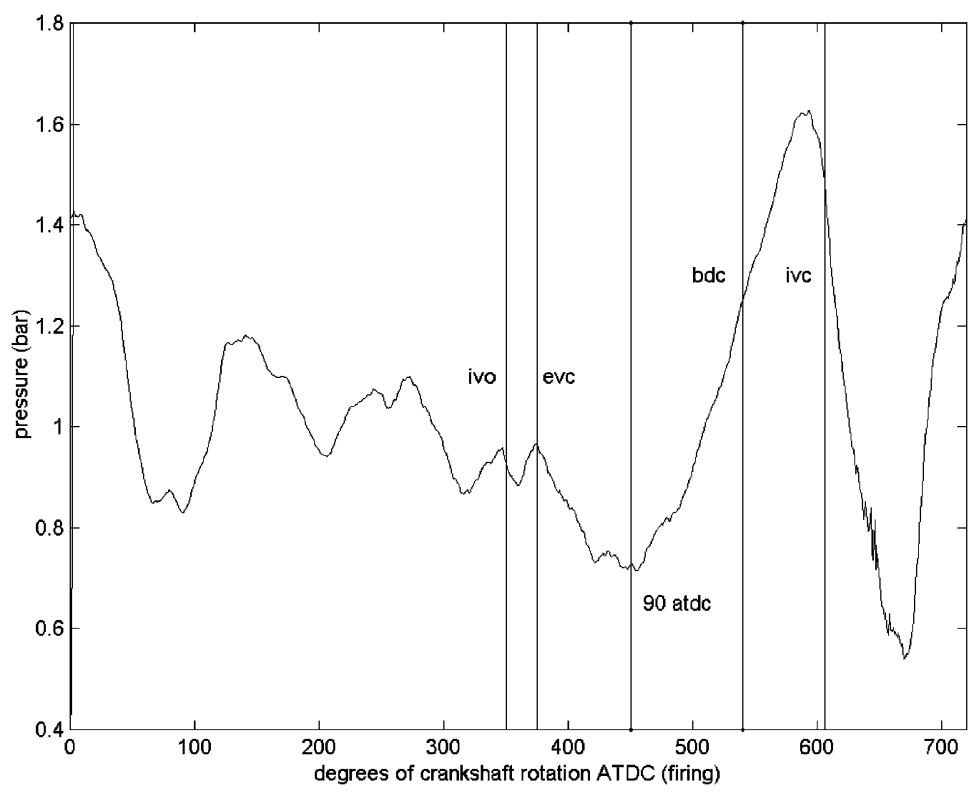

Fig. 4. Single cylinder Formula 1 engine. Measured intake port pressure $-13,000 \mathrm{rev} / \mathrm{min}$, wide open throttle.

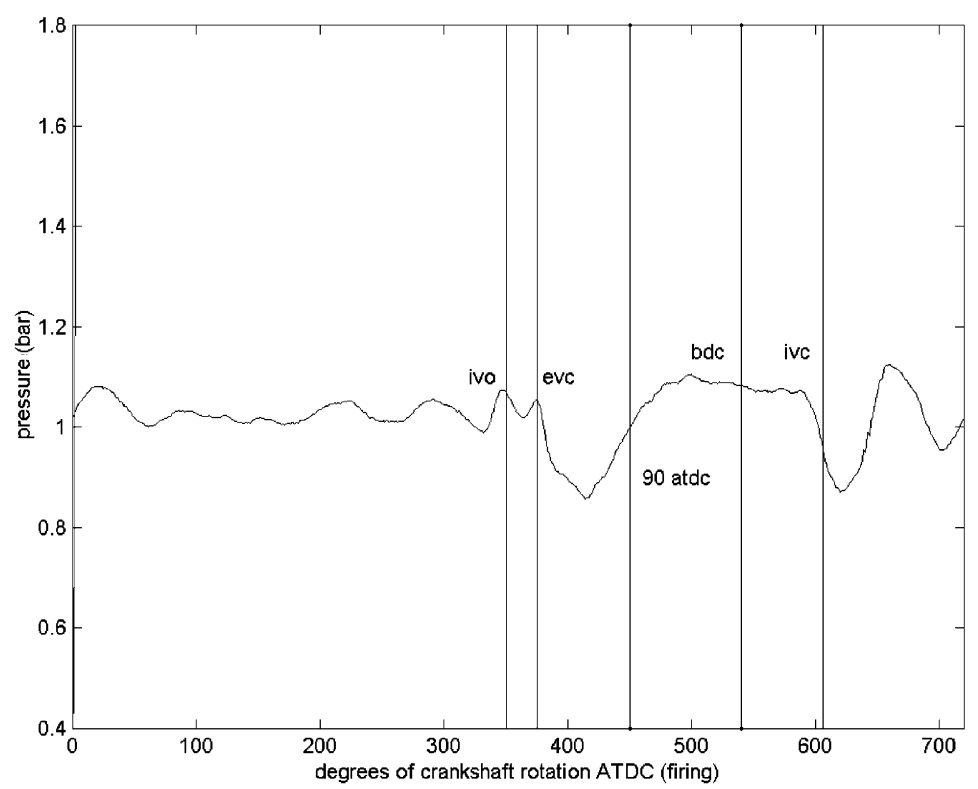

Fig. 5. Single cylinder Formula 1 engine. Measured intake port pressures $-7000 \mathrm{rev} / \mathrm{min}$ wide open throttle.

efficiency for the racing engine, and the inertial effects do seem to be more significant than the acoustic resonance effects.

The pressure record in Fig. 5 corresponds to the lowest practical speed for a racing engine (7000 rev/min) where the volumetric efficiency of the engine is known to be poor. The fact that it is 

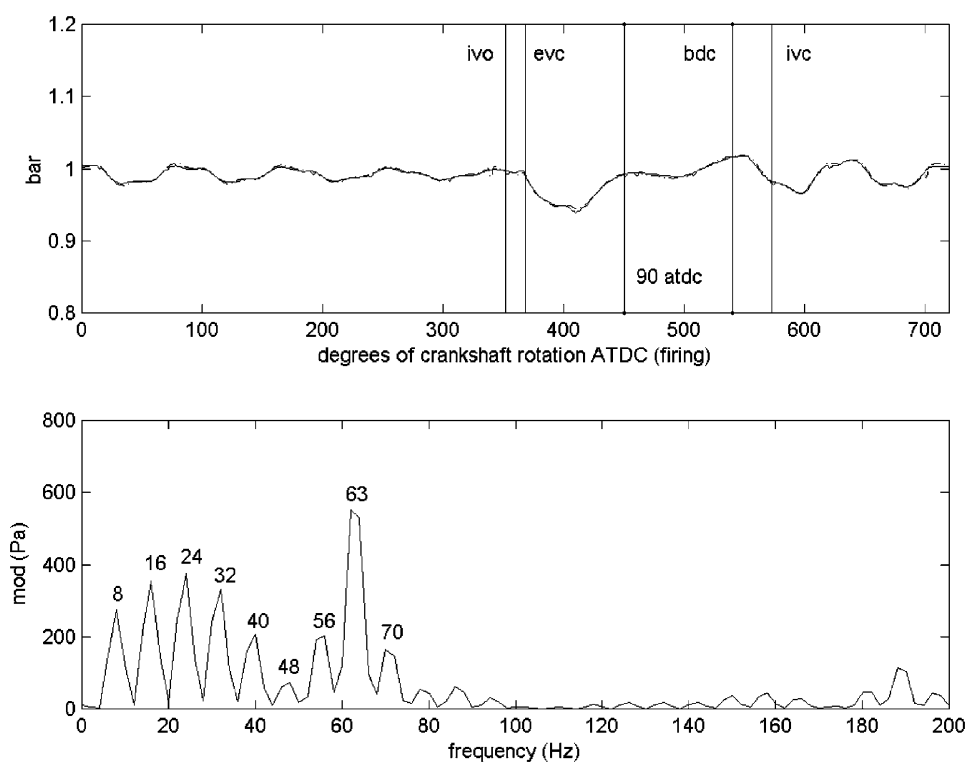

Fig. 6. Intake pressure record: low speed single cylinder engine with a long $(1.4 \mathrm{~m})$ straight pipe intake system. $1000 \mathrm{rev} / \mathrm{min}$ wide open throttle.

poor is not surprising as there is no evidence of inertial ram effects and only slight evidence of acoustic resonance effects as there is hardly any pressure peak before IVC. The pressure depression occurs before $90^{\circ}$ ATDC, an effect that has been noticed on another single cylinder engine operating at $1000 \mathrm{rev} / \mathrm{min}$ (the lowest practical running speed for that engine) as shown in Fig. 6. The pressure records in Figs. 5 and 6 have very similar features showing that poor volumetric efficiency at the lowest speeds corresponds to a pressure depression soon after IVO and very weak wave action to follow.

The frequency at which the pressure oscillates in the intake pipe of the racing engine has been estimated by finding the time interval between successive pressure minima in Figs. 4 and 5. At $13,000 \mathrm{rev} / \mathrm{min}$, the pressure oscillates at $600 \mathrm{~Hz}$ directly after IVC, then at $629 \mathrm{~Hz}$ for the next oscillation and then at $690 \mathrm{~Hz}$ for the last oscillation before IVO. So, the oscillation frequency varies during the cycle, the variation being some $15 \%$ when the valve is closed. This may simply be due to the variation in the flow Mach number which will drop from around $0.15 \mathrm{M}$ at IVC to near zero at the next IVO. The corresponding oscillation frequencies for the $7000 \mathrm{rev} / \mathrm{min}$ case are 506 , 525, 552, (362 Hz-double minimum present), $545 \mathrm{~Hz}$.

These variations in oscillation frequency were not found when the wave action was investigated in the intake system of a low speed engine [9].

The average pressure record from one cycle shown in Fig. 4 has been repeated many times to form a long data sequence. By using a moving Hanning window to produce the average of many 4096 point FFTs the spectrum shown in Fig. 7 was produced with a spectral resolution of $19 \mathrm{~Hz}$ due to the sample frequency being $78 \mathrm{kHz}$. The same technique applied to the data in Fig. 5 yields a spectrum of the intake pressure at $7000 \mathrm{rev} / \mathrm{min}$ with a frequency resolution of $10 \mathrm{~Hz}$ (the sample frequency being $42 \mathrm{kHz}$ ) as shown in Fig. 8. 


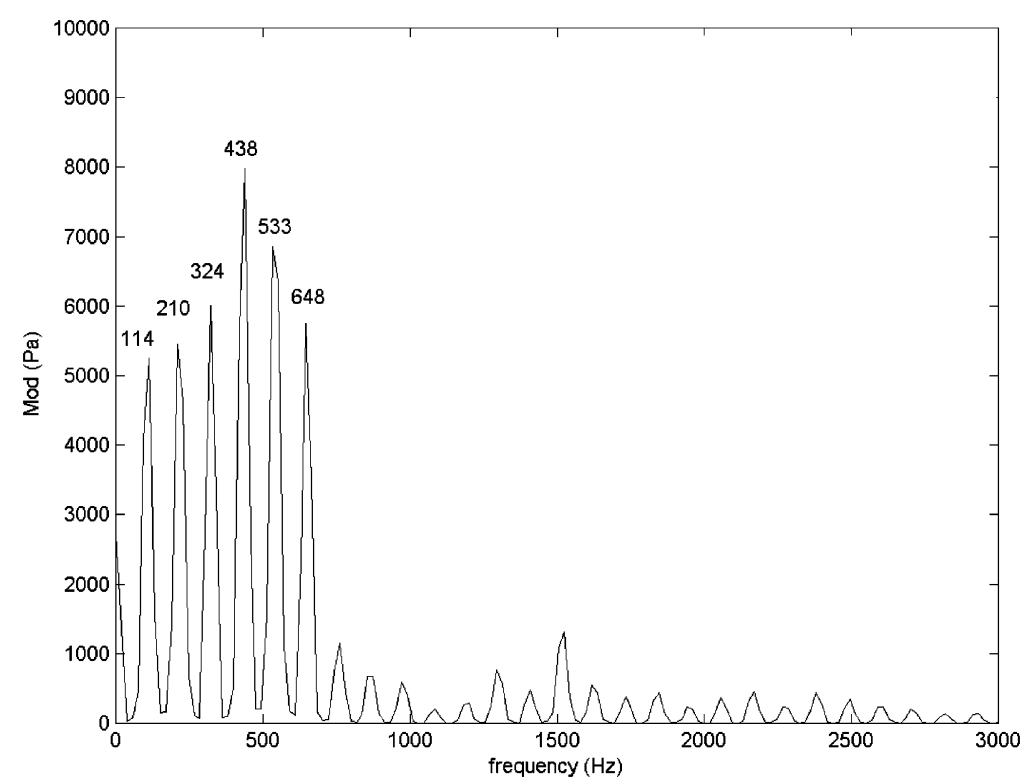

Fig. 7. Single cylinder Formula 1 engine. Measured intake port pressure spectrum-13,000 rev/min wide open throttle.

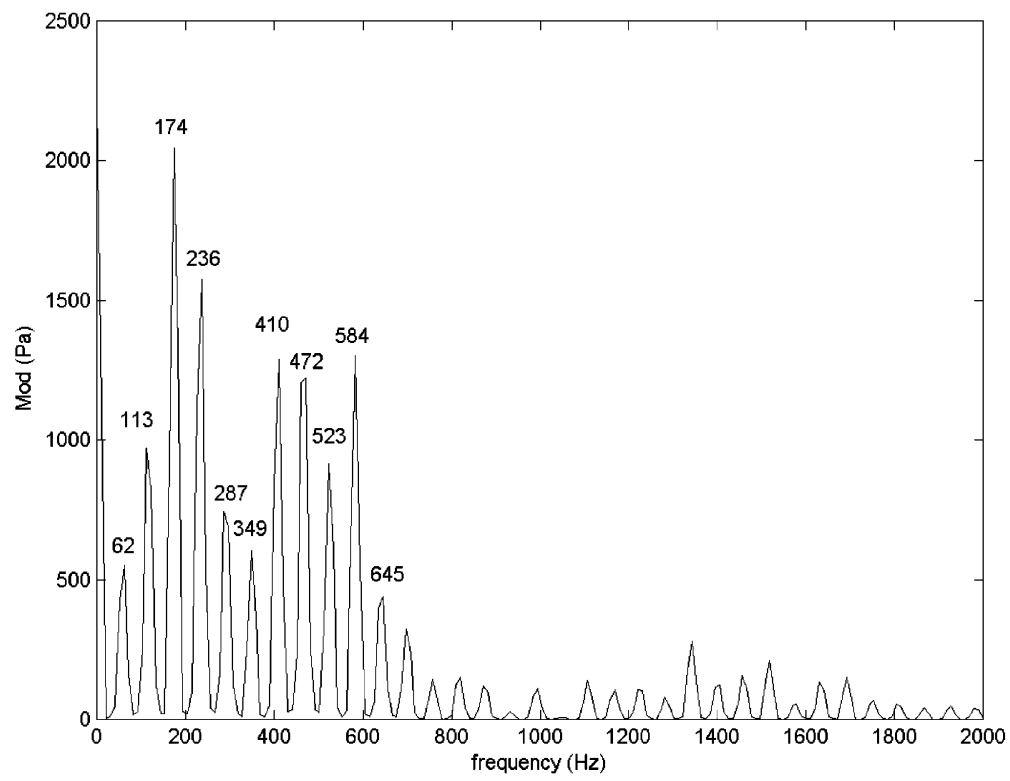

Fig. 8. Single cylinder Formula 1 engine. Measured intake port pressure spectrum-7000 rev/min wide open throttle.

Inspecting Fig. 7, the dominant frequency component of the intake pressure is $438 \mathrm{~Hz}$. This is the 4 th harmonic of the intake valve actuation frequency at $13,000 \mathrm{rev} / \mathrm{min}$. The other spectral components are the other integer harmonics of the cycle frequency $(1,2 \mathrm{nd}$, 3rd, etc.). The 
arithmetic mean of the closed valve oscillations is $640 \mathrm{~Hz}$ which is close to the 6 th harmonic of the cycle frequency $(648 \mathrm{~Hz})$.

Inspecting Fig. 8, the dominant frequency component of the intake pressure is $174 \mathrm{~Hz}$. This is the $3 \mathrm{rd}$ harmonic of the intake valve actuation frequency at $7000 \mathrm{rev} / \mathrm{min}$. As before, the other spectral components are the other integer harmonics of the cycle frequency. The arithmetic mean of the closed valve oscillations is $504 \mathrm{~Hz}$ which does not coincide with any of the harmonics of the cycle frequency. This suggests that any acoustic resonance present is only weak.

For a low speed single cylinder engine with a long straight pipe intake system, the following hypothesis was developed [9].

The early stages of the intake process are governed by the instantaneous values of the piston velocity and the open area under the valve. Thereafter the effects of acoustic resonance dominate the process. The depth of the early depression caused by the moving piston governs the intensity of the wave action that follows. A pressure ratio across the valve that is favourable to inflow is maintained and maximized when the open period of the valve is such to allow at least, but no more than, one complete oscillation of the pressure at its resonant frequency to occur whilst the valve is open.

The racing engine studied here deviates from that hypothesis in two ways. Firstly, at high speeds, inertial ram effects dominate the intake process rather than the seemingly weaker acoustic resonance effects. Secondly, at low speeds, there is no evidence of inertial ram effects and any acoustic resonance effects seem to be weak.

\section{Overview of the acoustic model}

The acoustic model employed for this study has been described in detail elsewhere [9], so only an overview of the calculation method will be given here. The model calculates the resonant response of the intake system, characterized by the pressure time history $P_{1}$ in the intake port, to a forcing due to the volume velocity $U_{1}$ passing through the intake valve.

The model may be described using the equivalent acoustic circuit shown in Fig. 9. The intake process involves two acoustic loads $Z_{e}$ and $Z_{1}$ acting on a volume velocity source of strength $V_{s}$ and producing the pressure $P_{1}$. The source impedance $Z_{e}$ is a function of the geometry of the opening and closing intake valve as well as the flow pattern between the intake port and the cylinder. Its physical location in the engine is shown in Fig. 10. The load impedance $Z_{1}$ is a function of the wave action in the intake port and in the rest of the intake system. Its physical location in the engine is also shown in Fig. 10.

After a study of the intake wave action in a low speed engine [9], it was determined that the influence of $Z_{e}$ must be small compared with the influence of $Z_{1}$ and therefore $Z_{e}$ could be

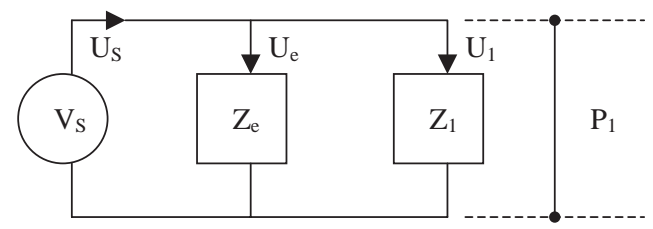

Fig. 9. Equivalent acoustic circuit for the intake process. 


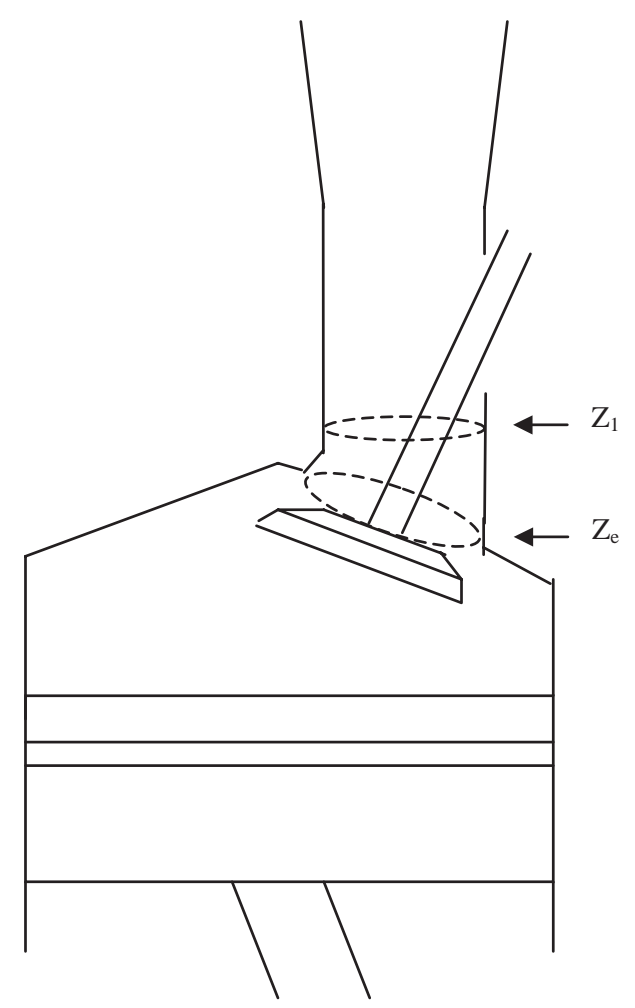

Fig. 10. Intake geometry and the physical location of the load impedance $Z_{1}$ and the source impedance $Z_{e}$.

neglected. Therefore, the intake problem reduces to the solution of:

$$
P_{1}=U_{s} Z_{1}
$$

The model adopted here can be described as a hybrid method [10] because it combines a time domain model for $U_{s}$ with a frequency domain model for $Z_{1}$ to produce a time domain calculation of $P_{1}$. However, it is more correctly described as an uncoupled hybrid method because it does not include the interaction between the engine as acoustic source $\left(U_{s}\right.$ and $\left.Z_{e}\right)$ and the acoustic load $\left(Z_{1}\right)$ imposed by the intake system.

In the uncoupled hybrid method, $U_{1}$ is estimated from engine geometry. In the true hybrid method $U_{1}$ is equal to $U_{s}-U_{e}$ and $U_{s}$ is a function of: cylinder dimensions (bore, stroke, compression ratio), engine speed, scavenging of residual exhaust gas (in turn a function of exhaust wave dynamics), valve geometry, valve timing, in-cylinder gas temperatures. $U_{e}$ is associated with flow losses in the valve.

Therefore, in essence the various hybrid methods in Refs. [11-19] calculate $U_{s}, U_{e}, Z_{e}, Z_{1}, U_{1}, P_{1}$ whereas in the uncoupled hybrid method used here $Z_{1}$ is calculated, $Z_{e}$ is neglected, $U_{1}$ is estimated and these are used to calculate an approximate $P_{1}$. 


\subsection{The model for volume velocity $U_{1}$}

An estimate for $U_{1}$ is calculated in two steps. A first estimate is obtained from

$$
U_{1}=\frac{\mathrm{d} V_{d}}{\mathrm{~d} t} \times \frac{S_{v}}{S_{1}}
$$

where $U_{1}$ is time varying and it is a function of the rate of change of cylinder volume $V_{d}$ and of the instantaneous flow area under the valve $S_{v}$ and of the intake port area $S_{1}$. The results from this calculation at 13,000 rev/min are shown in Fig. 11 (the dimensions of the engine geometry are not given here in order to respect the confidentiality of the engine builders). The second stage calculation is a scaling of the time history of flow area under the opening and closing intake valve(s) (obtained by calculating the curtain area around the base of the opening valve for every degree of crank-shaft rotation) so that the scaled results pass through the maximum value calculated from Eq. (2). No physical significance is placed on this choice of scaling, it is merely convenient and appears to be effective.

The results from the first and second stage estimates for $U_{1}$ are shown for a speed of 13,000 rev/ min in Fig. 12 and for $7000 \mathrm{rev} / \mathrm{min}$ in Fig. 13. In addition, measurements of $U_{1}$ are also presented [3] and the agreement between these and the second stage estimates are seen to be good in a general sense. However, the measured results clearly show a smaller amplitude oscillation superimposed on a larger amplitude envelope. In developing the models for estimating $U_{1}$ the uncoupled assumption was adopted and the effects of $Z_{e}$ were neglected. If the flow through the valve(s) were truly uncoupled from the wave action in the intake system then the detail of a good estimate for $U_{1}$ should agree with measured results. The presence of the smaller amplitude

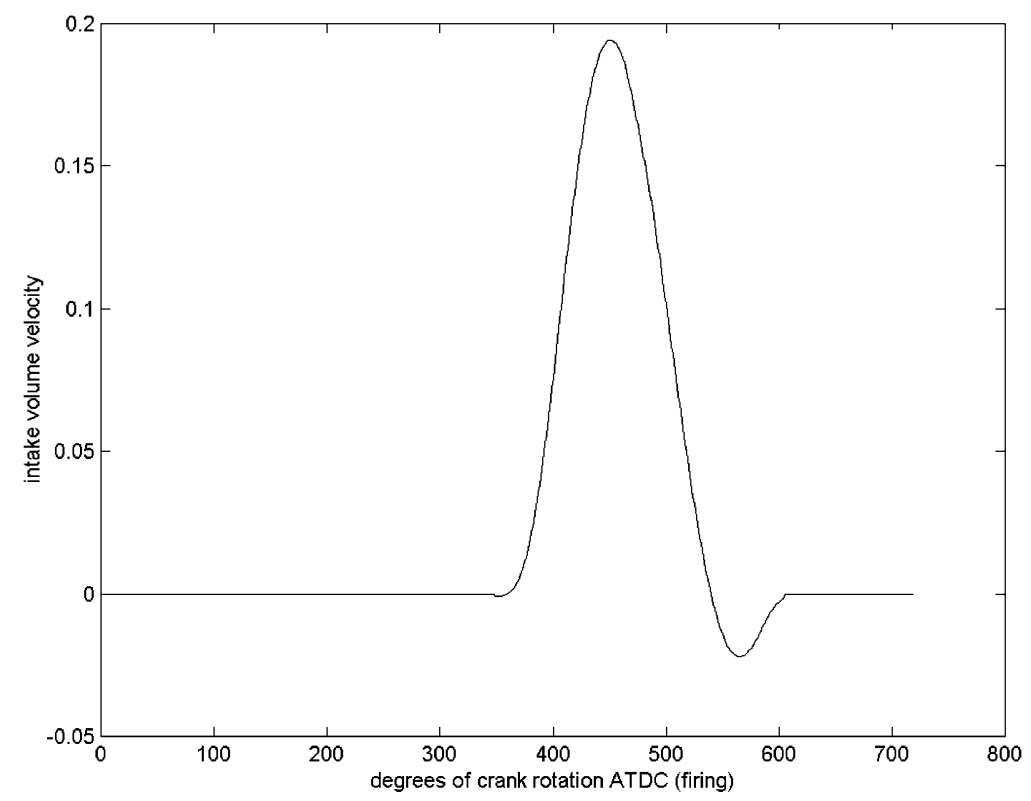

Fig. 11. Single cylinder Formula 1 engine. Calculated volume flow rate, $13,000 \mathrm{rev} / \mathrm{min}$ wide open throttle. 


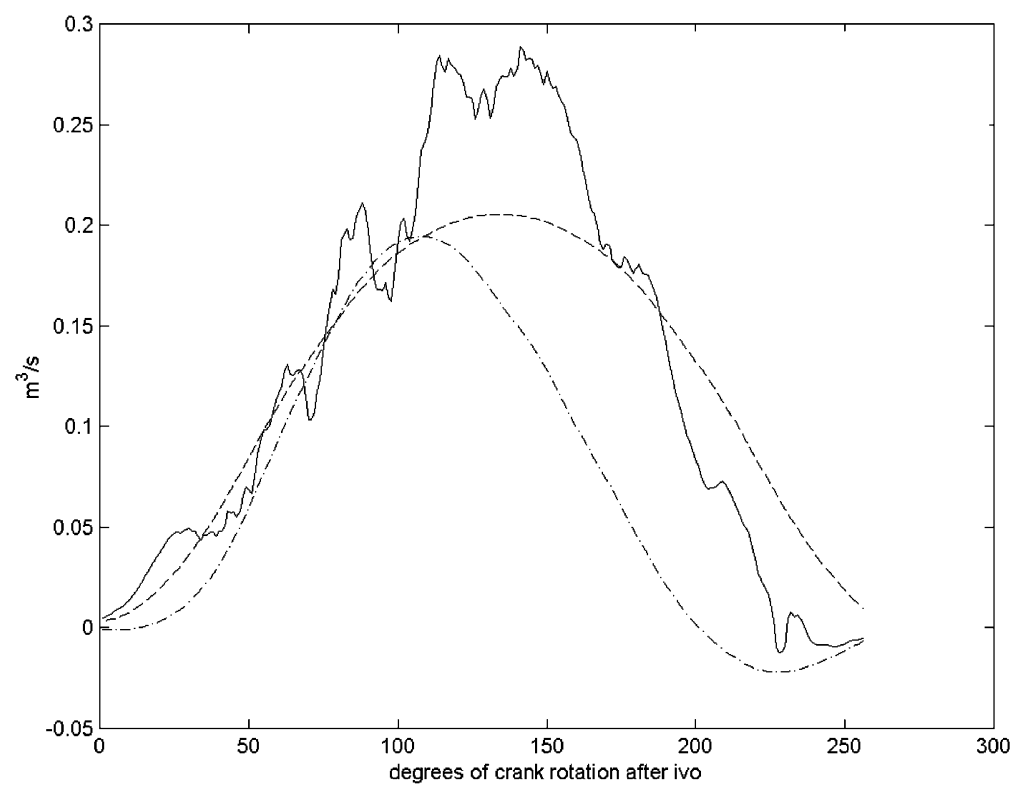

Fig. 12. Single cylinder Formula 1 engine. Calculated and measured volume flow rates, 13,000 rev/min wide open throttle. Measured (solid line), calculated from Eq. (2) (chain dotted line), calculated by scaling the open area under the lifting valve (dashed line).

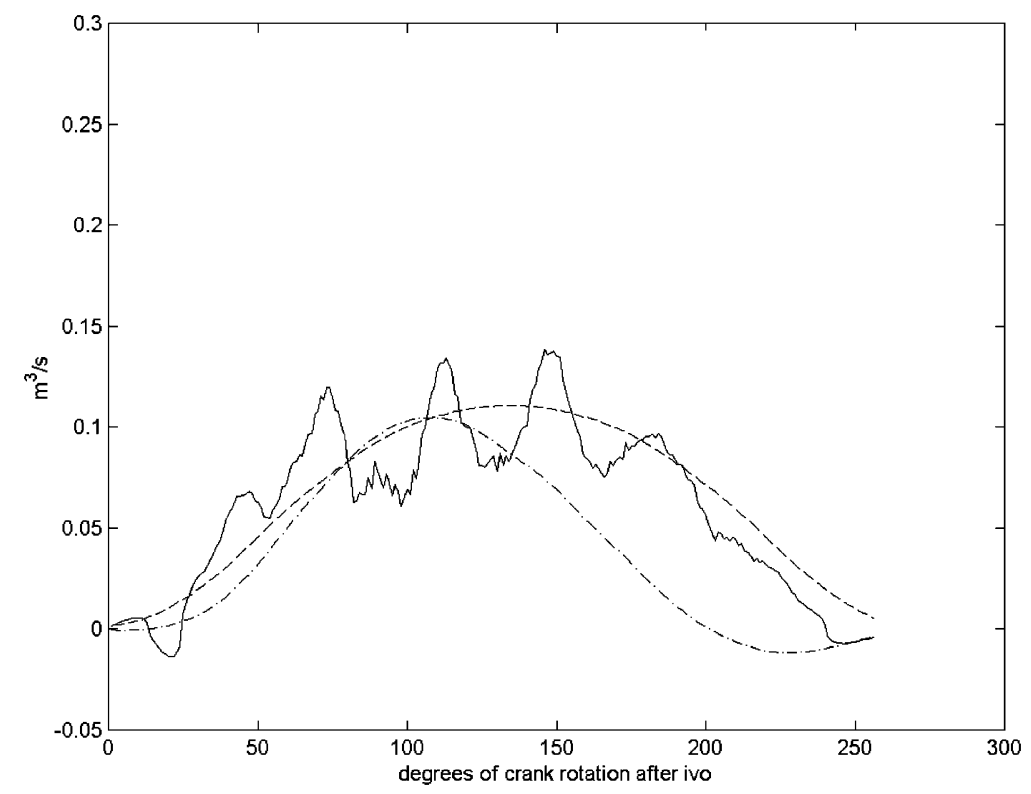

Fig. 13. Single cylinder Formula 1 engine. Calculated and measured volume flow rates, $7000 \mathrm{rev} / \mathrm{min}$ wide open throttle. Measured (solid line), calculated from Eq. (2) (chain dotted line), calculated by scaling the open area under the lifting valve (dashed line). 


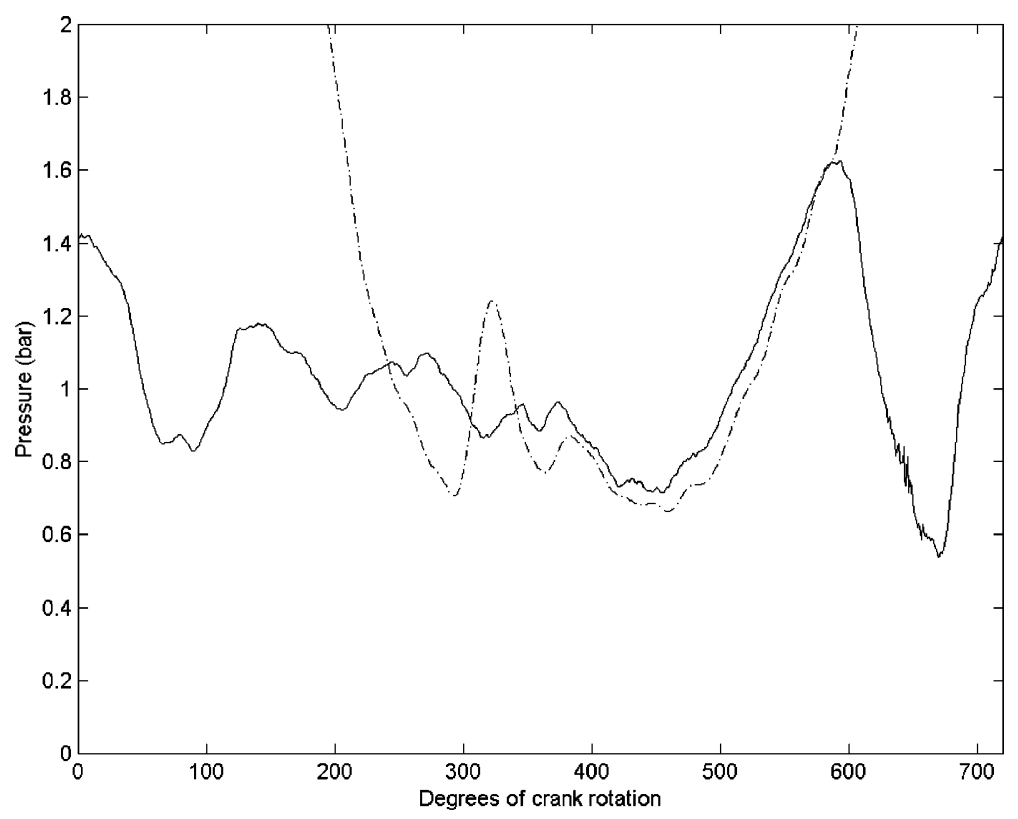

Fig. 14. Single cylinder Formula 1 engine. Measured intake port (solid line) and cylinder (chain dotted line) pressures, $13,000 \mathrm{rev} / \mathrm{min}$ wide open throttle.

oscillation in the measured results suggests that either the oscillation is due to the use of measured data acquired in the intake port rather than at the actual valve seat or there is some coupling present. If the latter is assumed to be true then $Z_{e}$ should be included in the model, but in the case of the high engine speed results its influence is of second order importance as the amplitude of the oscillation is small compared to the amplitude of the envelope. Inspecting Fig. 13, the influence of what might be assumed to be coupling is clearly more important at lower engine speeds. Notwithstanding this suggestion of some coupling between acoustic source and acoustic load, the uncoupled assumption is retained here as it allows the creation of a simple model that has proved to validate reasonably well against experiment.

To obtain the measurements of $U_{1}$ (the volume velocity through the intake valve, at a position in the intake port just behind the intake valve(s)) a calculation was made based on the pressure ratio across the opening and closing intake valve $[3,20]$. The inputs to this calculation are simultaneous measurements of the cylinder pressure and of the pressure in the intake port just behind the intake valve(s) (Figs. 14 and 15). These require some careful cross-calibration to overcome DC drift problems commonly encountered with cylinder pressure measurements as described in Ref. [20]. The measured pressure ratio across the intake valve may be used in a classical model for the flow through poppet valves [21] to calculate the mass flow rate through the valve:

$$
\dot{m}=\frac{P_{c} A_{e}}{c_{c}}\left[\left(\frac{2 \gamma^{2}}{\gamma-1}\right)\left(\frac{P_{1}}{P_{c}}\right)^{2 / \gamma}\left[1-\left(\frac{P_{1}}{P_{c}}\right)^{(\gamma-1) / \gamma}\right]\right]^{1 / 2},
$$




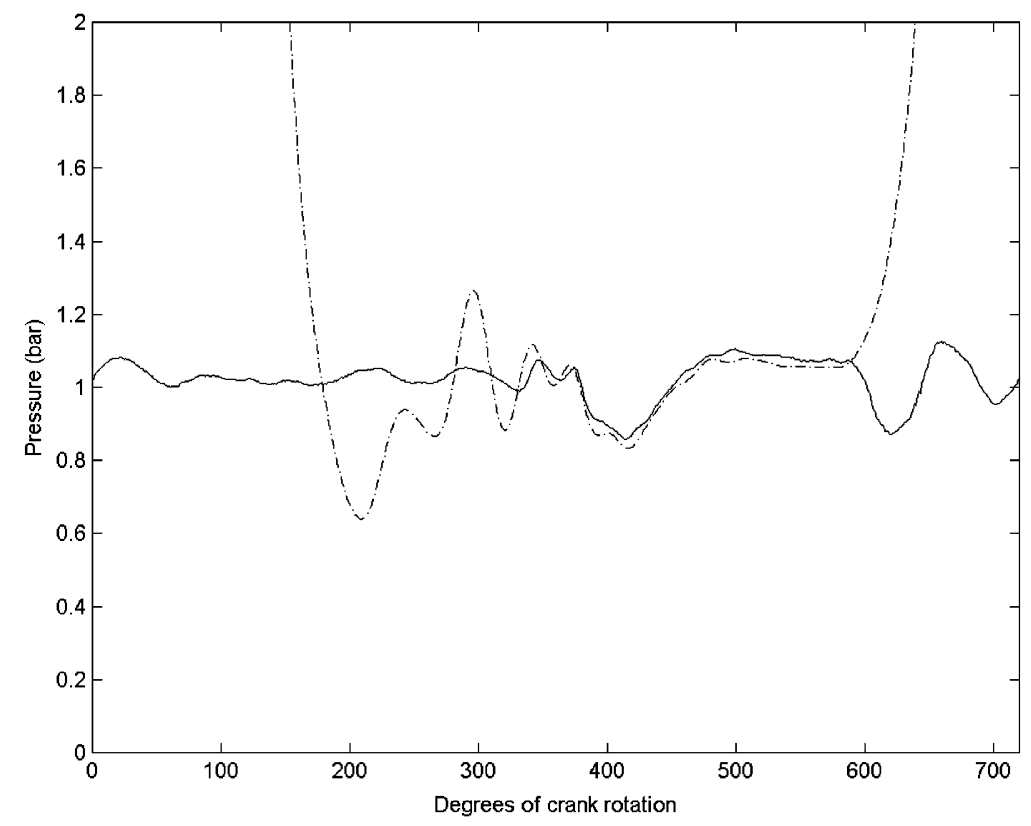

Fig. 15. Single cylinder Formula 1 engine. Measured intake port (solid line) and cylinder (chain dotted line) pressures, $7000 \mathrm{rev} / \mathrm{min}$ wide open throttle.

where $P_{c}$ is the cylinder pressure $(\mathrm{Pa}), P_{1}$ the intake port pressure $(\mathrm{Pa}), c_{c}$ the speed of sound in the cylinder, $A_{e}=A_{m} C, A_{m}$ the valve open area $\left(\mathrm{m}^{2}\right)$, and $C$ the flow loss coefficient (measured on a flow bench).

By assuming stagnation conditions in the cylinder, and by using the value for the prevailing stagnation density, the volume velocity through the intake valve can be calculated as shown in Figs. 12 and 13.

The second-stage estimate of $U_{1}$ from Fig. 12 has been interpolated so that it forms part of a 64 point data sequence to describe the $720^{\circ}$ of crank-shaft rotation for the four-stroke cycle as shown in Fig. 16. The single calculated cycle shown in Fig. 12 was repeated many times in a long sequence and by using a moving Hanning window to produce an average of many 1024 point FFTs the spectrum shown in Fig. 16 was produced with a spectral resolution of around $7 \mathrm{~Hz}$ due to the sample frequency being $6933 \mathrm{~Hz}$. It is clear that every integer harmonic of the valve actuation frequency of $108 \mathrm{~Hz}$ is present in this spectrum. This explains the presence of these spectral components in the corresponding intake port pressure spectrum shown in Fig. 7.

\subsection{The model for the acoustic load impedance $Z_{1}$}

A one-dimensional, linear, plane-wave, frequency domain model of the simplified intake system shown in Fig. 3 has been prepared [9,22]. 

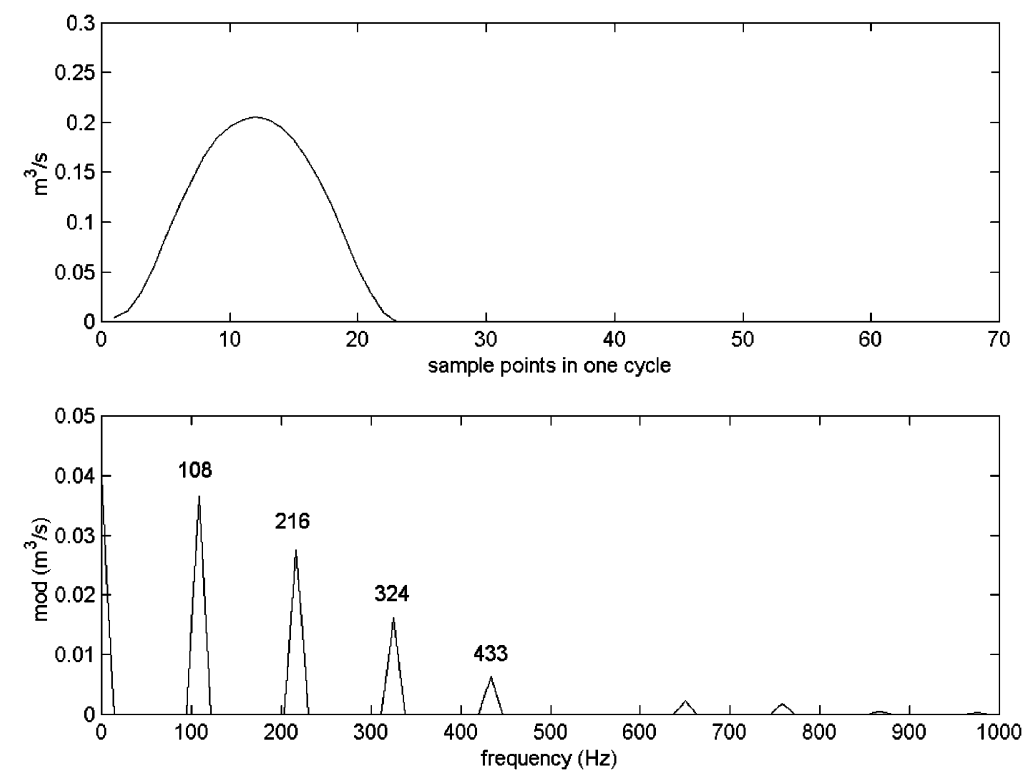

Fig. 16. Single cylinder Formula 1 engine. Spectrum of the estimated volume velocity in the intake port, 13,000 rev/min wide open throttle.

The starting point for the acoustic calculations is the known reflection coefficient at the open end of the long air-horn

$$
r_{4}=\frac{p_{4}^{-}}{p_{4}^{+}} .
$$

That reflection coefficient is known for the case of inflow to a pipe with a slight bellmouth, where there is no flow separation on entry and the flow outside of the pipe is essentially stagnant [22]. The reflection coefficient varies with Mach number in the pipe as well as being subject to the addition of a small end correction to the length of the pipe to take account of the phase of $r_{4}$. As a result, two calculations are performed [9], one for the open valve condition where the mean Mach number in the short intake pipe is high $(0.13 \mathrm{M})$ and one for the closed valve condition when the mean Mach number in the short intake pipe is low $(0.05 \mathrm{M})$.

An acoustic transfer is made between $r_{4}$ at the open end to $r_{1}$ at the intake valve position

$$
r_{1}=\frac{p_{1}^{-}}{p_{1}^{+}}
$$

where the effects of pipe lengths, sudden expansions and sudden contractions in the flow duct are considered [22]. The final result is the specific acoustic impedance ratio

$$
\zeta_{1}=\frac{\left(1+r_{1}\right)}{\left(1-r_{1}\right)}
$$

where

$$
Z_{1}=\zeta_{1} \rho_{o} c_{o} S_{1}
$$



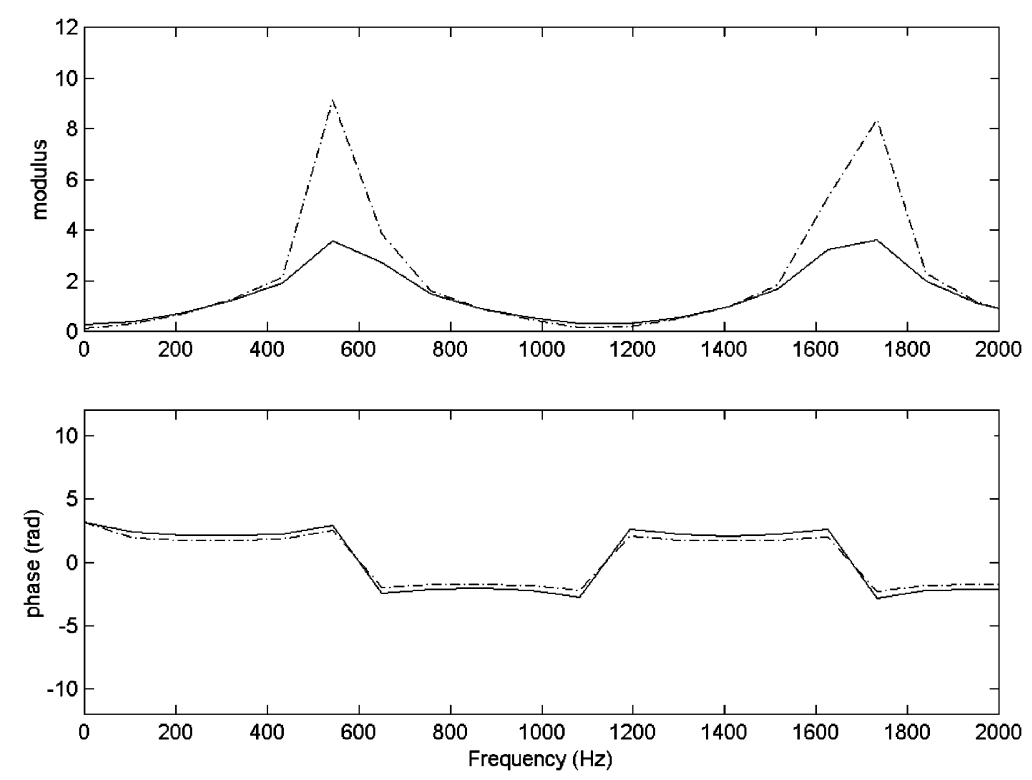

Fig. 17. Single cylinder Formula 1 engine. Calculated specific acoustic impedance ratio for the full intake system, 13,000 rev/min wide open throttle. Open intake valve (solid line), closed intake valve (chain dotted line).

where $c_{o}$ is the stagnation sound speed, $\rho_{o}$ the stagnation speed density, and $S_{1}$ the cross-sectional area of the intake port.

The specific acoustic impedance ratios corresponding to the open and closed valve cases at 13,000 rev/min are shown in Fig. 17. The increased mean Mach number in the open valve case reduces the magnitude of the acoustic impedance at the two resonant frequencies $(542,1733 \mathrm{~Hz})$ which are clearly shown as peaks in the impedance.

\subsection{Calculating the intake port pressure $P_{1}$}

Following on from Eq. (1):

$$
P_{1}(t)=\operatorname{IFFT}\left[U_{1}(f) Z_{1}(f)\right]
$$

$U_{1}(f)$ is found by taking a single 64 point FFT of the 64 points used in the model to describe $U_{1}$ for one cycle as shown in Fig. 16. In order to obtain the product in Eq. (8), the specific acoustic impedance ratio spectra shown in Fig. 17 should be re-calculated to be a 64 point double sided spectra with a resolution that matches $U_{1}(f)$.

The inverse Fourier transform of Eq. (8) must be performed twice, once for the open valve values of $Z_{1}$ and once for the closed valve values. The resulting time histories of $P_{1}$ are shown for 13,000 rev/min in Fig. 18.

In order to complete the calculation of $P_{1}$, the 64-point sequences from Eq. (8) must first be interpolated to 720-point sequences, one value for each degree of crank-shaft rotation in the fourstroke cycle. The first few data points from the open valve sequence correspond to the values of $P_{1}$ for the interval IVO-IVC. The corresponding values from the closed valve sequence are discarded. 


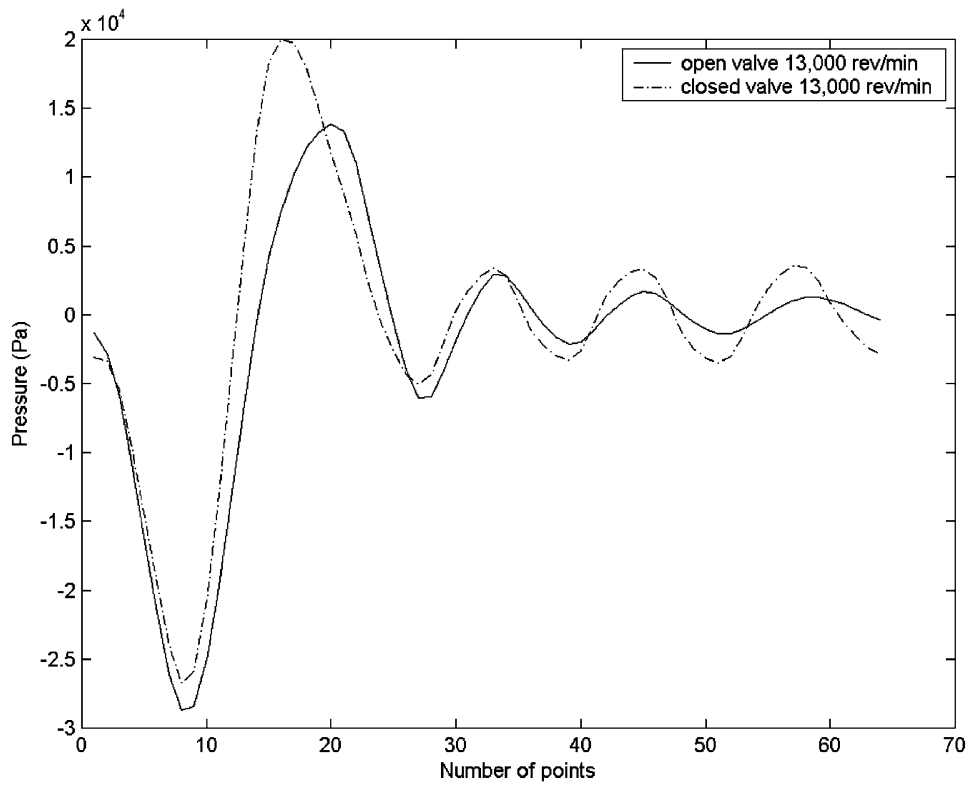

Fig. 18. Single cylinder Formula 1 engine. Calculated fluctuations in intake port pressure, 13,000 rev/min wide open throttle. Open intake valve (solid line), closed intake valve (chain dotted line).

The remaining values from the closed valve sequence correspond to the values of $P_{1}$ for the period when the valve is closed. The pressure in the intake system will be the composite $P_{1}$ added to the prevailing static pressure. The final composite curve will exhibit discontinuities at both IVO and IVC. These are evident by close inspection of the results presented in this paper as no attempts to smooth the transitions have been made.

\section{Results and discussion}

\subsection{Results obtained using the acoustic model}

The acoustic model described in Section 3 has been used to calculate the pressure $P_{1}$ in the intake port of the racing engine sketched in Fig. 1. This has been done for two engine speeds. The first at 13,000 rev/min corresponds to a speed at which very high volumetric efficiency is expected, and the second at $7000 \mathrm{rev} / \mathrm{min}$ is the lowest practical running speed for this engine. The calculated intake port pressure at 13,000 rev/min is shown in Fig. 19 along with the measured average pressure record from Fig. 4. There are some important differences in the results.

Firstly, when the valve is closed, the calculation results show a decaying pressure oscillation with a frequency of $565 \mathrm{~Hz}$ for the first cycle of oscillation after IVC. The frequency was obtained using the method described in Section 2 and is close to both the 5th harmonic of the cycle frequency at $540 \mathrm{~Hz}$ and to the lowest resonant frequency of the intake system at $542 \mathrm{~Hz}$. The frequency for the first cycle of oscillation in the measured data was found to be $600 \mathrm{~Hz}$. For the 


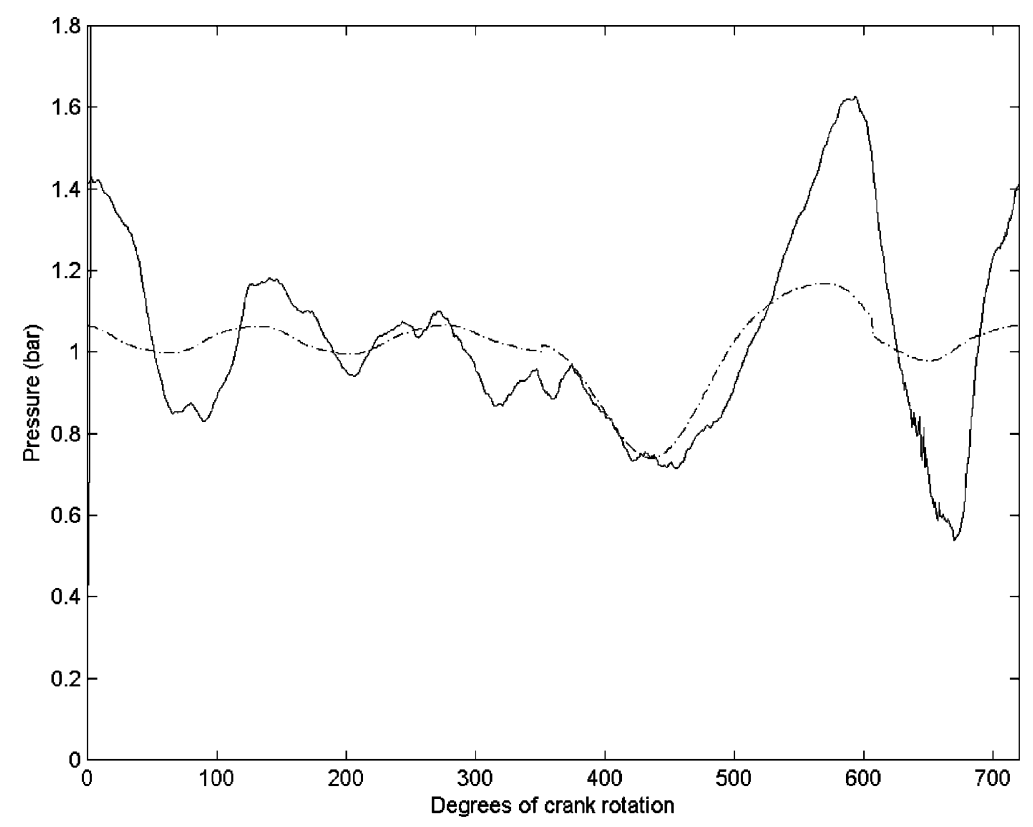

Fig. 19. Single cylinder Formula 1 engine. Measured (solid line) and calculated (chain dotted line) intake port pressures, 13,000 rev/min wide open throttle.

second cycle of oscillation, the calculated frequency is $574 \mathrm{~Hz}$ and the measured frequency is $629 \mathrm{~Hz}$. Therefore, the stretching of the pressure wavelength as the oscillation decays after IVC first noted in the experimental results is reproduced to some small degree by the calculation. However, the resonant frequencies shown in the calculated results are too low. The acoustic length of the intake pipe must be shorter than the $150 \mathrm{~mm}$ plus end correction assumed in the modelling (the end correction being $13.8 \mathrm{~mm}$ at the lowest Helmholtz number and $10.5 \mathrm{~mm}$ at the highest).

The second difference is that the inertial ram effects suggested in the measured data and discussed in Section 2 are not included in the calculated results and therefore the calculated pressure peak just before IVC is lower. The reason for this is straightforward. The acoustic model calculates the resonant pressure response of the intake system to a volume velocity excitation and any momentum transfer (the inertial ram effect) from the mean flow is not included in the model. It seems from the results in Fig. 19 that this momentum transfer has the effect of adding to the pressure peak just before IVC caused by acoustic resonance effects. Because the amplitude of the pressure peak just before IVC is lower in the calculated results, the amplitude of the pressure peaks that follow in the period IVC-IVO are also lower.

Fig. 20 shows a comparison between calculated and measured intake port pressures at $7000 \mathrm{rev} /$ min. This time the decaying pressure oscillation after IVC in the calculated results has cycle frequencies of $575,538,591,538,575 \mathrm{~Hz}$, respectively. These compare to the frequencies discussed in Section 2 which were 506, 525, 552, (362 Hz-double minimum present), $545 \mathrm{~Hz}$. There is a variation in oscillation frequency in both cases although the rather unusual 4th oscillation found in the measured results is not replicated by the calculation and therefore the overall agreement is reduced. The intake behaviour at low speeds seems to be fairly well modelled and therefore the 


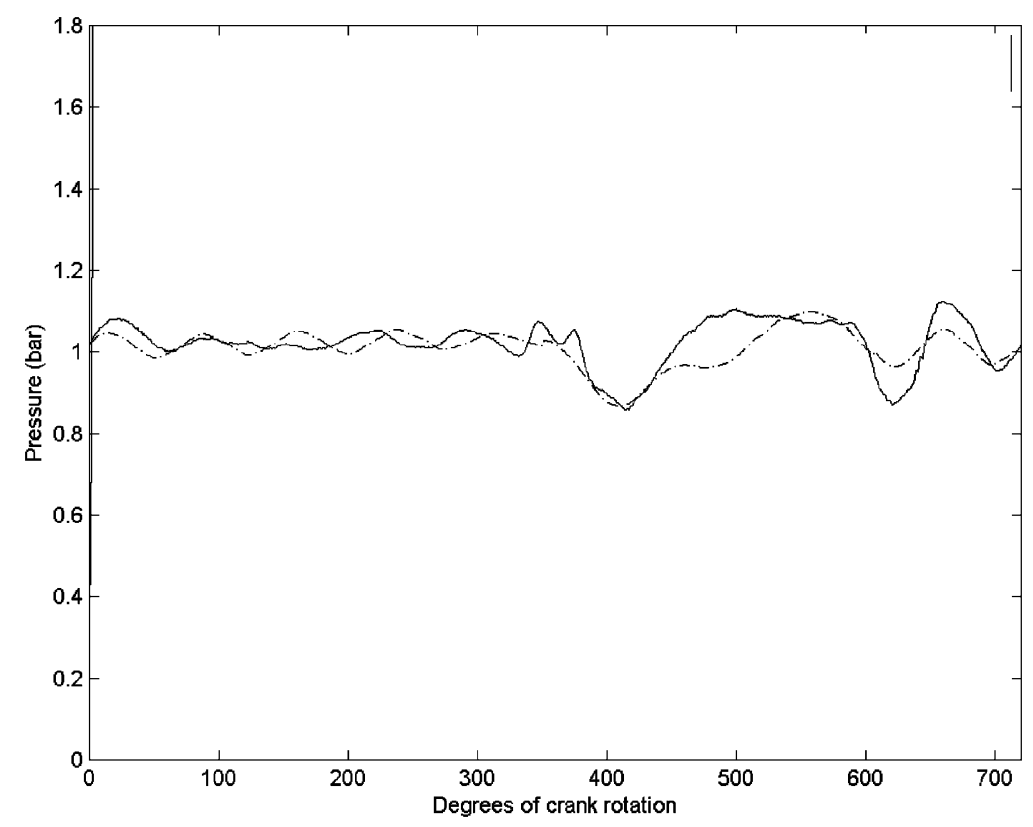

Fig. 20. Single cylinder Formula 1 engine. Measured (solid line) and calculated (chain dotted line) intake port pressures, $7000 \mathrm{rev} / \mathrm{min}$ wide open throttle.

effect of weak acoustic resonance seems to dominate the behaviour, in contrast to the strong inertial ram effect suspected at higher speeds.

\subsection{Results that include a simple model of the inertia ram effect}

The discussion in Section 4.1 highlights the need to include the inertial ram effect in a calculation of the high speed inlet flow to a racing engine. Therefore, the acoustic model described in Section 3 has been extended with the simplest possible model of the inertial ram effect. The momentum $\Phi$ of the intake flow is taken to be:

$$
\Phi=\rho_{0} S_{1} l_{1} u_{1},
$$

where $\rho_{0}$ is the stagnation density of the inlet air $\left(\mathrm{kg} \mathrm{m}^{-3}\right), S_{1}$ the effective cross-sectional area of conical of inlet pipe $\left(\mathrm{m}^{2}\right), l_{1}$ the length of inlet pipe (m), and $u_{1}$ is the flow velocity in the intake pipe $\left(\mathrm{m} \mathrm{s}^{-1}\right)$

$$
u_{1}(t)=\frac{U_{1}(t)}{S_{1}} .
$$

The transfer of momentum as the intake flow is brought to rest on the back of the closing valve causes a rise in pressure $P_{I R}$ due to the inertial ram effect given by

$$
P_{I R}(t)=\frac{\mathrm{d} \varphi}{\mathrm{d} t} \times \frac{1}{S_{1}} .
$$




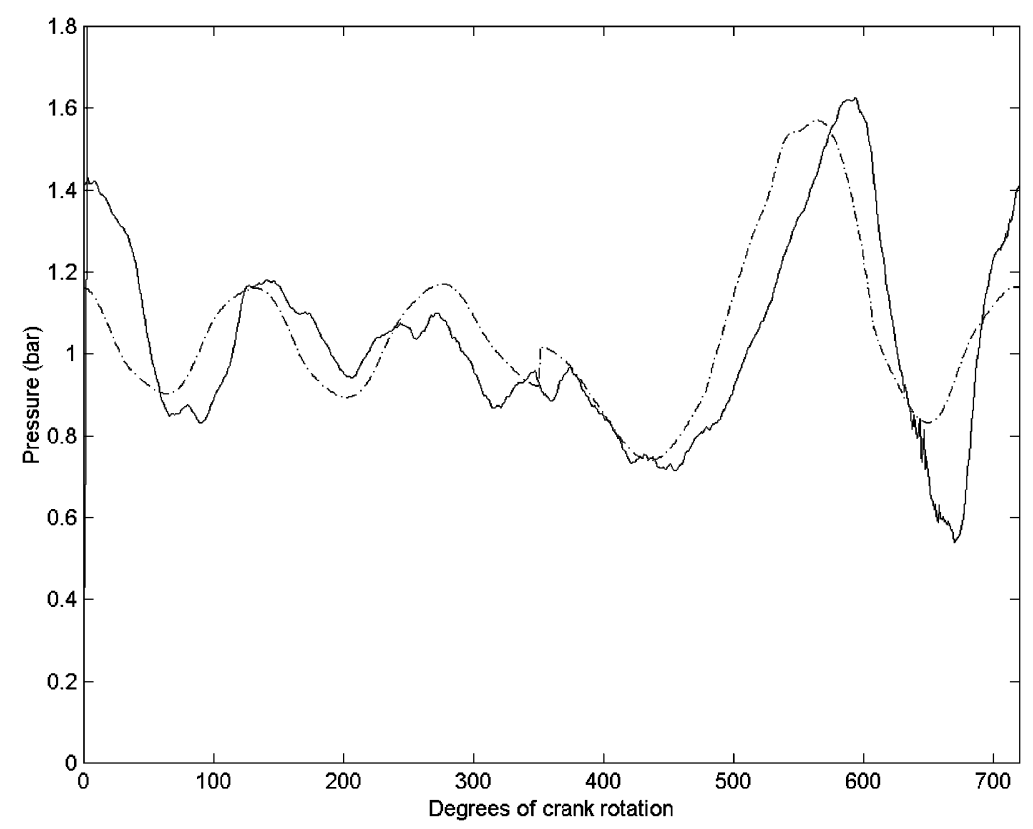

Fig. 21. Single cylinder Formula 1 engine. Measured (solid line) and calculated (chain dotted line) intake port pressures, 13,000 rev/min wide open throttle, including a model for inertial ram effects.

The simplifying assumption made here is that the flow is incompressible, therefore there is a constant density equal to $\rho_{0}$ down the length of the intake pipe. The dominant pressure fluctuation occurs at around $600 \mathrm{~Hz}$ and therefore the length of the $150 \mathrm{~mm}$ intake pipe is around $1 / 4$ of the dominant wavelength. This is too high a proportion of one wavelength to support the simplifying assumption, but because of its ease of use it will be retained until a better alternative is developed.

Fig. 21 shows the results of the extended calculation method at $13,000 \mathrm{rev} / \mathrm{min}$. The inertial ram effect has been included only for the portion of the period IVO-IVC where the valve is closing. In addition, the results in the period IVC-IVO have been scaled by the factor

$$
\text { factor }=\frac{\left[\left(P_{1}\right)_{\max }+\left(P_{I R}\right)_{\max }\right]_{I V O-I V C}}{\left[\left(P_{1}\right)_{\max }\right]_{I V O-I V C}}
$$

to reflect the increased pressure pulse around IVC that immediately precedes the period IVCIVO. The agreement between calculated and measured results is much better for the extended model than was obtained using the acoustic model described in Section 3. The need to include even the simplest model of the inertial ram effect at high engine speeds such as this one is clear.

Fig. 22 shows the results obtained from the extended model at $7000 \mathrm{rev} / \mathrm{min}$. The added inertial ram effects are clearly too strong in this low speed case. Unfortunately, there is no means at present of predicting the onset of the inertial ram effect with increasing speed. A simple rule of including inertial ram effects at speeds above say $2 / 3$ of the rated engine speed might prove acceptable in practice but there is no physical justification for this. 


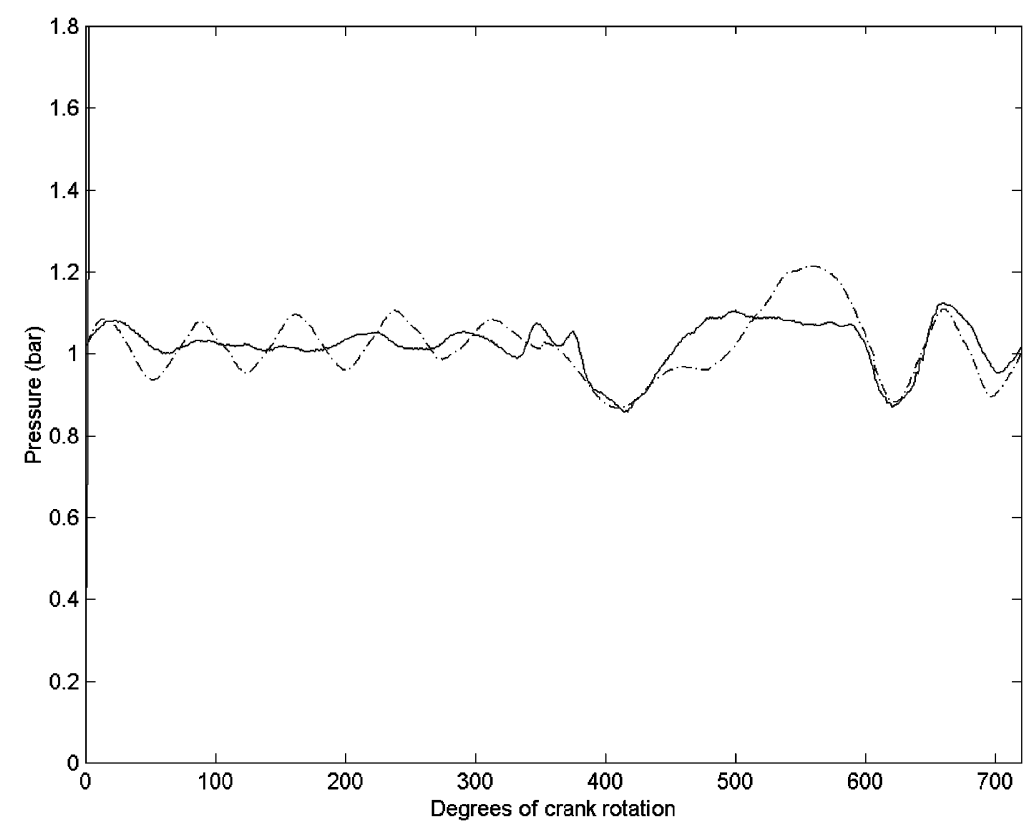

Fig. 22. Single cylinder Formula 1 engine. Measured (solid line) and calculated (chain dotted line) intake port pressures, $7000 \mathrm{rev} / \mathrm{min}$ wide open throttle, including a model for inertial ram effects.

An alternative form of validation of the extended calculations is offered. The spectra of calculated and measured intake port pressures are compared in Figs. 23 and 24. These spectra have been produced by repeating the single cycle data from Figs. 21 and 22 many times to form long data sequences. By using a moving Hanning window to produce averages of many 4096 point FFTs the spectra shown in Figs. 23 and 24 were produced with a spectral resolution of 19 and $10 \mathrm{~Hz}$, respectively due to the sample frequency being 78 and $42 \mathrm{kHz}$, respectively. In both speed cases, the calculated sound pressure level is within $5 \mathrm{~dB}$ of the measured value for the majority of the first ten harmonics of the cycle frequency.

The agreement between measured and the calculated results is fair. Any lack of agreement might be due to: oversimplification of the acoustic model where wide-angle cones were modelled as straight pipes of the same length, oversimplification of the effects of unsteady flow modelled as an equivalent mean flow, the use of a reflective boundary at the open end which has not been validated at high Mach numbers and with high sound levels, oversimplified modelling of the inertial ram effects, or the effects of flow induced noise.

A comment is offered on the usefulness of the extended acoustic model presented here. It is fair to say that a time domain solution to the equations of fluid motion offers the best way to calculate both acoustic resonance and inertial ram effects together. The use of such an approach has been discussed in the introduction to this paper and some validation of the results is offered there. However, it is impossible to distinguish between the acoustic resonance effects and the inertial ram effects with such an approach, whereas the extended acoustic model does allow that distinction, albeit in a rather simplified form. 


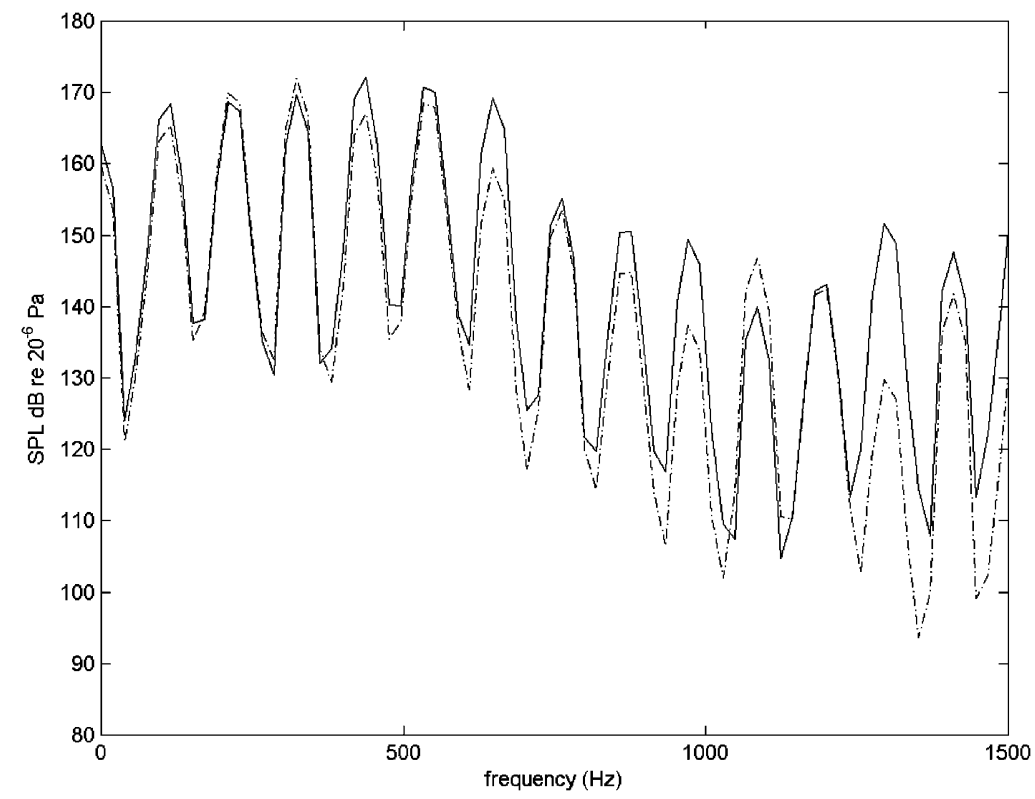

Fig. 23. Single cylinder Formula 1 engine. Measured (solid line) and calculated (chain dotted line) intake port pressure spectra, 13,000 rev/min wide open throttle, including a model for inertial ram effects.

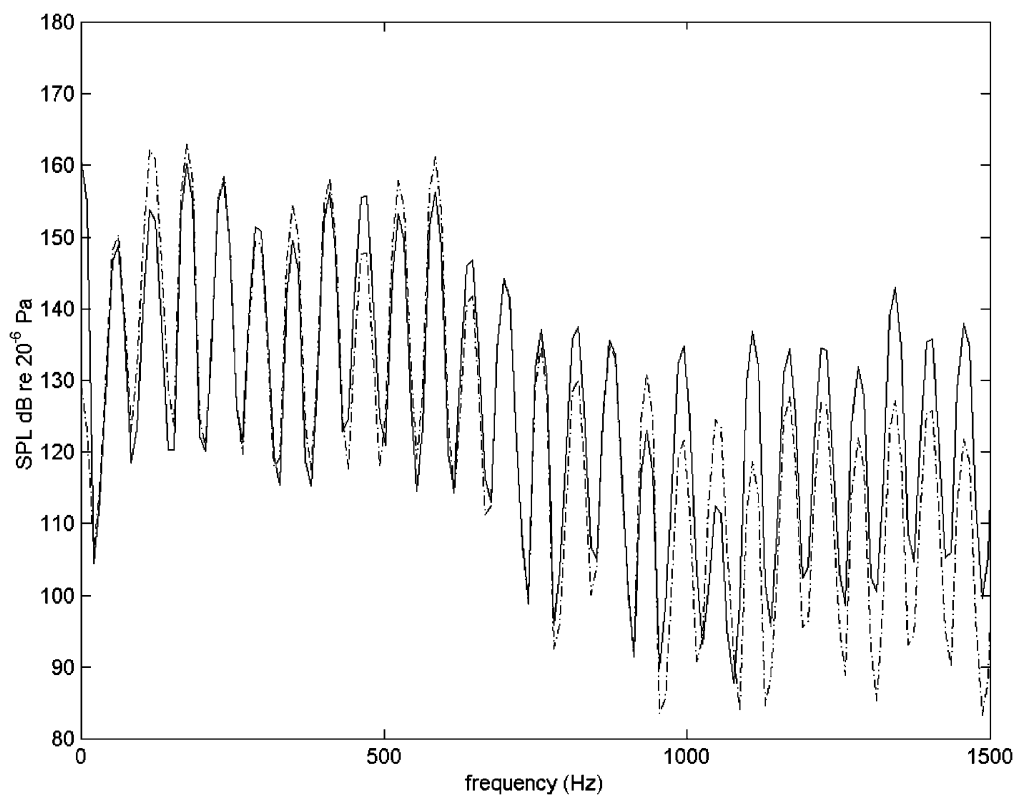

Fig. 24. Single cylinder Formula 1 engine. Measured (solid line) and calculated (chain dotted line) intake port pressure spectra, $7000 \mathrm{rev} / \mathrm{min}$ wide open throttle, including a model for inertial ram effects. 


\subsection{A case study: the influence of the intake plenum}

To illustrate how the extended linear acoustic model might be used to better understand the intake wave action in a racing engine, a case study is offered where the decoupling effect of the plenum used in the intake of the single cylinder engine sketched in Fig. 1 is assessed.

The acoustic characteristics of the simplified model of the single cylinder intake system shown in Fig. 3 can be described thus.

The maximum attenuation of the sound wave emanating from the intake valve is due to the plenum and is given by

$$
\text { Attenuation }=20 \log _{10} \frac{p_{1}^{+}}{p_{2}^{+}} \approx 20 \log _{10} \frac{S_{2}}{S_{1}}=12 \mathrm{~dB} .
$$

This will only be obtained at frequencies away from resonance in the plenum. Assuming a parallel-piped plenum, these resonant frequencies can be estimated from

$$
\begin{gathered}
f=\frac{n c}{2 x}, \quad n=1,2,3, \ldots, \quad x=0.41 \mathrm{~m}, \quad c=343 \mathrm{~m} / \mathrm{s}, \\
f_{1}=418 \mathrm{~Hz}, \quad f_{2}=836 \mathrm{~Hz}, \quad f_{3}=1672 \mathrm{~Hz} .
\end{gathered}
$$

The attenuation of the plenum at these resonant frequencies will tend to zero $\mathrm{dB}$.

The intake wave action is expected at a frequency that is near to the lowest resonant frequency of the short intake pipe, given by [9]

$$
\begin{gathered}
f=\frac{n c}{4 x} \quad n=1,3,5 \ldots, \quad x=0.15 \mathrm{~m}, \quad c=343 \mathrm{~m} / \mathrm{s} \\
f_{1}=572 \mathrm{~Hz}, \quad f_{2}=1716 \mathrm{~Hz}
\end{gathered}
$$

The resonant frequency of $572 \mathrm{~Hz}$ is neatly between the two lowest resonant frequencies of the plenum $(418$ and $836 \mathrm{~Hz}$ ) and so the attenuation of the plenum should be near $12 \mathrm{~dB}$ at $572 \mathrm{~Hz}$. Therefore, the plenum ought to decouple the wave action in the short intake pipe from the wave action in the rest of the intake system. If the short intake pipe had been any longer (say $200 \mathrm{~mm}$ ) then the two resonant frequencies would have coincided and the decoupling would be expected to be poor.

This simple analysis suggests that the plenum will decouple the intake pipe from the rest of the intake system when a $410 \mathrm{~mm}$ long, $300 \mathrm{~mm}$ diameter plenum is used with a $150 \mathrm{~mm}$ long, $50 \mathrm{~mm}$ diameter intake pipe. Thus, any differences in the indicated mean effective pressures measured on the single cylinder engine and on the V10 ought not to be due to differences in intake wave action, but perhaps differences in exhaust wave action.

However, this simple analysis is not completely reliable as it is hard to judge exactly which frequency components will dominate the wave action in the intake system.

The acoustic model can be used to assess the effect of the plenum directly. Figs. 25 and 26 show a comparison of calculated results where the whole intake system has been modelled and other results where only the $150 \mathrm{~mm}$ intake pipe has been modelled. The fact that there are only slight differences between the two sets of results suggests that the decoupling achieved by the 30 litre plenum is strong but not perfect. Therefore, there may be slight variations in the intake behaviour of the single cylinder engine when compared with V10 engines either on the dynamometer or 


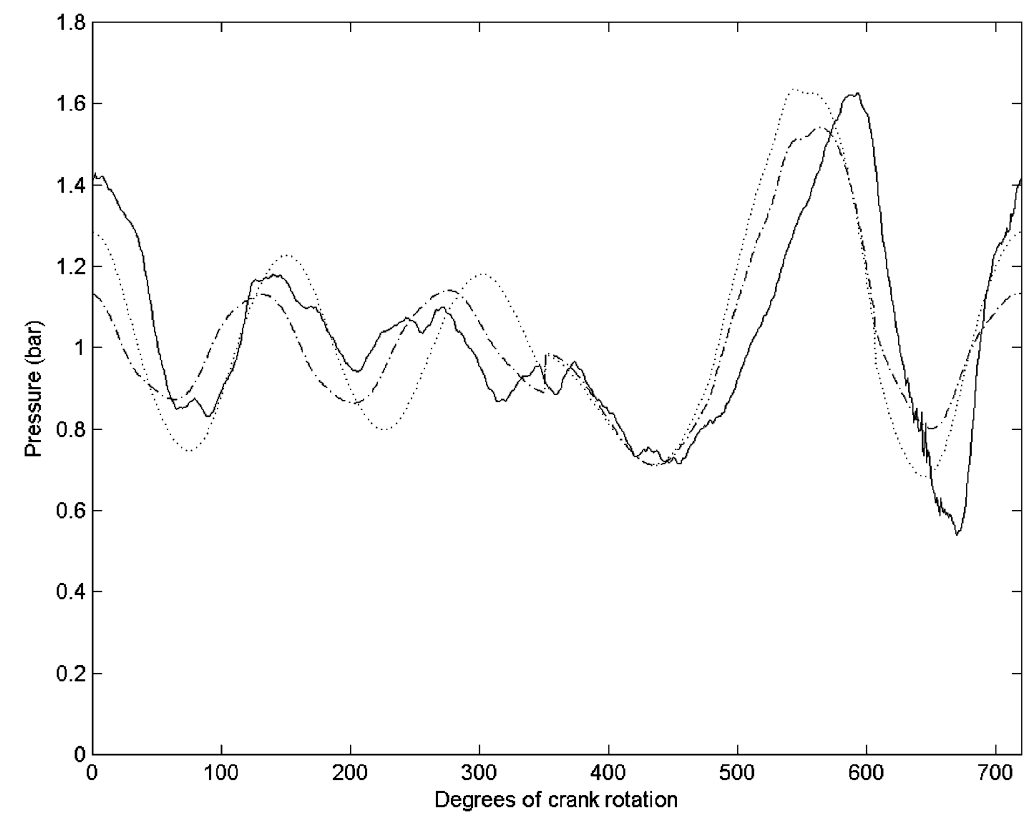

Fig. 25. Single cylinder Formula 1 engine. Measured (solid line) and calculated intake port pressures, 13,000 rev/min wide open throttle. Calculated results are for models that include the full intake system (chain dotted line) and models that only consider the $150 \mathrm{~mm}$ long intake pipe/port (dashed line). Both sets of calculated results include a model for inertial ram effects.

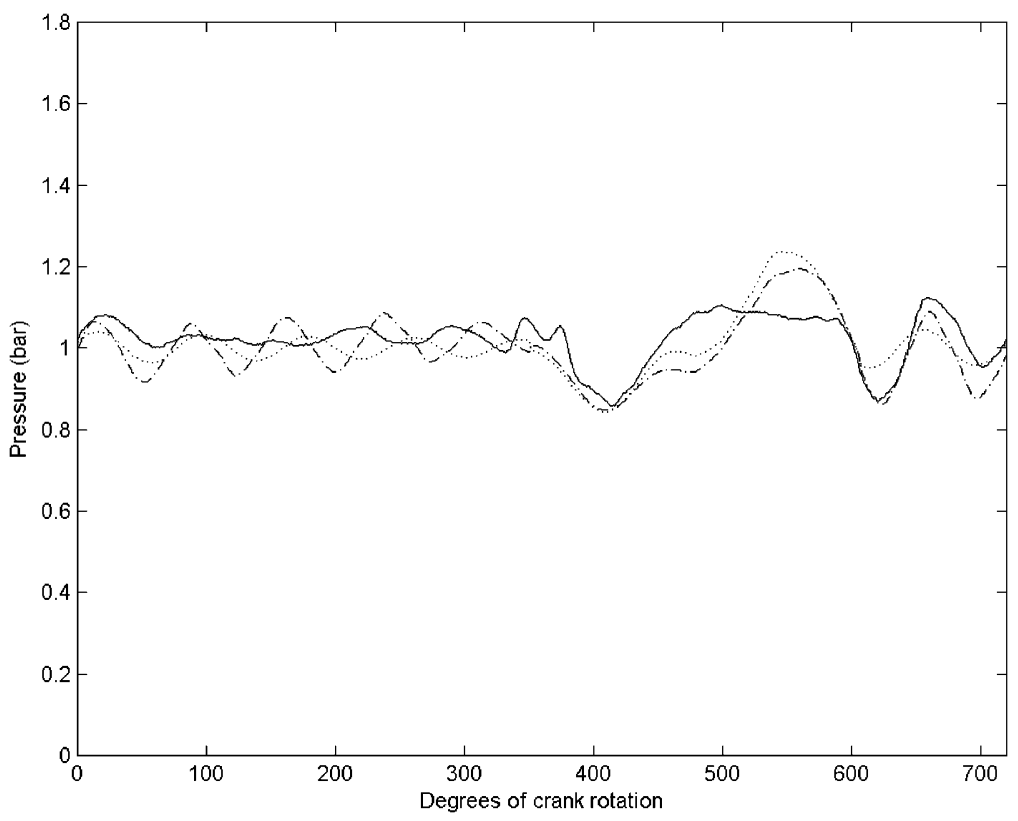

Fig. 26. Single cylinder Formula 1 engine. Measured (solid line) and calculated intake port pressures, 13,000 rev/min wide open throttle. Calculated results are for models that include the full intake system (chain dotted line) and models that only consider the $150 \mathrm{~mm}$ long intake pipe/port (dashed line). Both sets of calculated results include a model for inertial ram effects. 
installed in the car, assuming that the decoupling provided by the 30 litre V10 airbox is equally strong. These variations will only be small and will only be responsible for minor differences in indicated mean effective pressure. Any significant differences in engine performance are likely to be due to some other factor such as differences in the exhaust action.

\section{Conclusions}

An investigation into the intake process on a single cylinder racing engine has shown that inertial ram effects make a strong contribution to the intake process at high engine speeds whereas acoustic resonance effects are more important to the rather weak wave action that occurs at low engine speeds.

An acoustic model of the acoustic resonance effect has proved useful in distinguishing between these two mechanisms. A simple model of the inertial ram effect has also proved useful.

A decoupled hybrid method has been shown to yield calculations of the wave dynamics in the intake system of a single cylinder racing engine that show at least fair agreement with measured results up to the 10th harmonic of the engine cycle frequency.

The intake characteristics of a single cylinder racing engine have been shown to be only slightly different from those expected from a V10 engine due to the decoupling effects of the plenum fitted to the intake of the single cylinder engine and the airbox fitted to the V10.

\section{Acknowledgements}

The authors thank Ilmor Racing Engines for their permission to publish the second author's measured data in this paper.

The first author gratefully acknowledges the support of EPSRC for the theoretical aspects of this work made possible under grant No. GR/R04324.

\section{References}

[1] D.E. Winterbone, R.J. Pearson, Theory of Engine Manifold Design: Wave Action Methods for IC Engines, Professional Engineering Publishing Ltd, London, 2000.

[2] X.F. Ferlet, Computer Simulation of Combustion and Gas Dynamics in Racing Engines, PhD Thesis, University of Manchester, Institute of Science and Technology, 1995.

[3] Alex Dunkley, The acoustics of IC engine manifolds, MSc Thesis, Cranfield University, 2000.

[4] D. Cottyn, Concept design of a single cylinder F1 research engine, MSc Thesis, Cranfield University, 2002.

[5] E.S. Dennison, Inertia supercharging of engine cylinders, Transactions of the American Society of Mechanical Engineers Oil Gas and Power 55 (1933) 53-64.

[6] A. Capetti, Effects of intake pipe on the volumetric efficiency of an internal combustion engine (translation), NACA TM 501, February 1929.

[7] C.F. Taylor, J.C. Livengood, D.H. Tsai, Dynamics in the inlet system of a four-stroke single cylinder engine, Transactions of the American Society of Mechanical Engineers 77 (1955) 1133-1145.

[8] P. Giannattasio, A. Dadone, Applications of a high resolution shock-capturing scheme to the unsteady flow computation in engine ducts, IMEchE International Conference on Computers in Engine Technology, Cambridge England, 1991, pp. 119-126. 
[9] M.F. Harrison, P.T. Stanev, Alinear acoustic model for intake wave dynamics in IC engines, Journal of Sound and Vibration $269(1+2)(2004) 361-387$.

[10] A.D. Jones, Modelling the exhaust noise radiated from reciprocating internal combustion engines - a literature review, Noise Control Engineering 23 (1) (1984) 12-31.

[11] P.O.A.L. Davies, M.F. Harrison, Predictive acoustic modelling applied to the control of intake/exhaust noise of internal combustion engines, Journal of Sound and Vibration 202 (2) (1997) 249-274.

[12] W.M. Wang, Acoustical analysis of a multi-cylinder engine air-induction system, Journal of the Acoustical Society of America 42 (6) (1967) 1244-1249.

[13] L. Desmons, J. Kergomard, Simple analysis of exhaust noise produced by a four cylinder engine, Applied Acoustics 41 (1994) 127-155.

[14] M.R. Driels, Dynamics of IC engine induction systems, Journal of Sound and Vibration 43 (3) (1975) 499-510.

[15] F. Payri, J.M. Desantes, A.J. Torregrosa, Acoustic boundary conditions for unsteady one-dimensional flow calculations, Journal of Sound and Vibration 188 (1) (1995) 85-110.

[16] J.M. Desantes, A.J. Torregrosa, A. Broatch, Hybrid linear/non-linear method for exhaust noise prediction, SAE Paper No 950575, 1995.

[17] Y. Sathyanarayana, M.L. Munjal, A hybrid approach for aeroacoustic analysis of the engine exhaust system, Applied Acoustics 60 (2000) 425-450.

[18] F. Albertson, J. Gilbert, The acoustic balance method for predicting the sound from a piston-restriction system, Seventh International Congress on Sound and Vibration 4-7 July 2000, p. 1725-1732.

[19] F. Albertson, J. Gilbert, Harmonic balance method used for calculating the steady-state oscillations of a simple one-cylinder cold engine, Journal of Sound and Vibration 241 (4) (2001) 541-565.

[20] M.F. Harrison, P.T. Stanev, Measuring wave dynamics in IC engine intake systems, Journal of Sound and Vibration $269(1+2)(2004)$ 389-408.

[21] T.C. Tsu, Theory of the inlet and exhaust processes of internal combustion engines, NACA TN 1446, 1947.

[22] P.O.A.L. Davies, Practical flow duct acoustics, Journal of Sound and Vibration 124 (1) (1998) 91-115. 